\title{
Review Article \\ Recent Advances in Electrode Materials with Anion Redox Chemistry for Sodium-Ion Batteries
}

\author{
Natalia Voronina (D) and Seung-Taek Myung \\ Hybrid Materials Research Center, Department of Nano Technology and Advanced Materials Engineering, Sejong Battery Institute, \\ Sejong University, Seoul 05006, Republic of Korea \\ Correspondence should be addressed to Seung-Taek Myung; smyung@sejong.ac.kr
}

Received 30 April 2021; Accepted 3 July 2021; Published 30 July 2021

Copyright ( 2021 Natalia Voronina and Seung-Taek Myung. Exclusive Licensee Beijing Institute of Technology Press. Distributed under a Creative Commons Attribution License (CC BY 4.0).

The development of sodium-ion batteries (SIBs), which are promising alternatives to lithium-ion batteries (LIBs), offers new opportunities to address the depletion of $\mathrm{Li}$ and Co resources; however, their implementation is hindered by their relatively low capacities and moderate operation voltages and resulting low energy densities. To overcome these limitations, considerable attention has been focused on anionic redox reactions, which proceed at high voltages with extra capacity. This manuscript covers the origin and recent development of anionic redox electrode materials for SIBs, including state-of-the-art P2- and O3type layered oxides. We sequentially analyze the anion activity-structure-performance relationship in electrode materials. Finally, we discuss remaining challenges and suggest new strategies for future research in anion-redox cathode materials for SIBs.

\section{Introduction}

Lithium-ion batteries (LIBs) are one of the most efficient energy storage devices to power not only portable electronics but also electric vehicles owing to their high energy density and good cycle life. The electrification of vehicles has confirmed the feasibility of LIBs as medium- or large-scale energy devices; hence, the application of LIBs is being expanded toward grid-scale applications to store electricity generated from renewable applications or power plants. This rising demand directly affects the fluctuation of prices of raw materials such as lithium, cobalt, and nickel resources. Economical and ethical concerns for mining raw materials encourage us to search for alternatives to LIBs. Recently, sodium-ion batteries (SIBs) have reemerged as alternatives to LIBs $[1,2]$, with emphasis on the merit of the raw material costs; namely, lithium resources are unevenly distributed on the Earth's crust, whereas sodium is present everywhere. Expensive cobalt and nickel elements are the main redox centers for LIBs, whereas inexpensive manganese-based moieties can provide stable electrochemical activity for SIBs. Because of the difference in the standard electrode potential between $\mathrm{Li}(-3.04 \mathrm{~V}$ versus standard hydrogen electrode (SHE)) and $\mathrm{Na}(-2.7 \mathrm{~V}$ versus SHE), there is evident loss of energy density for SIBs compared to that for LIBs when assuming that both systems deliver the same specific capacity [3]. This fact encourages the rational design of high-capacity cathode materials for SIBs to achieve capacities that are comparable to those for LIBs.

The large sodium ion (1.02 $\AA$ ) can be stabilized in both prismatic $(\mathrm{P})$ and octahedral $(\mathrm{O})$ environments in layered structures, in which the former has a larger sodium layer than the latter owing to the size of the prismatic environment. The oxygen stacking sequence is combined with the environment of sodium ions in the sodium layer, for example, P2, P3, and O3, as proposed by Delmas et al. [4]. O3 layer compounds are stabilized when the sodium content ranges between 0.9 and 1 in $\mathrm{Na}_{x} T M \mathrm{O}_{2}$ (TM: metal), where the TM has an average oxidation state of $\sim 3+$; however, sodium-deficient $\mathrm{Na}_{x} \mathrm{TMO}_{2}(0.7 \leq x \leq 0.4)$ compounds are crystallized into P2 and P3 structures that show average oxidation states of Me over 3.3+. This affects the first charge capacity; namely, the first discharge capacity is always higher than the charge capacity for P2 and P3 compounds because of the sodium deficiency in the sodium layers. Thus, additional presodiation or the use of additives is needed to increase the first charge capacity and achieve a coulombic efficiency (CE) close to $1[5,6]$. The large size of sodium ions also induces successive structural changes during the extraction and insertion of sodium ions. The resulting interlayer distance of the $\mathrm{O} 3$ layer 


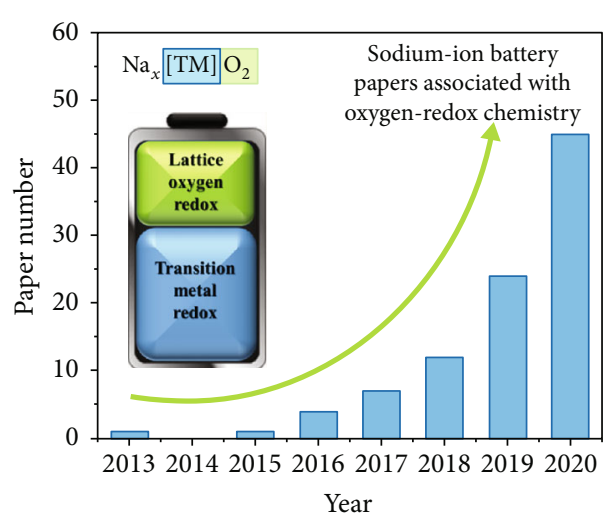

(a)

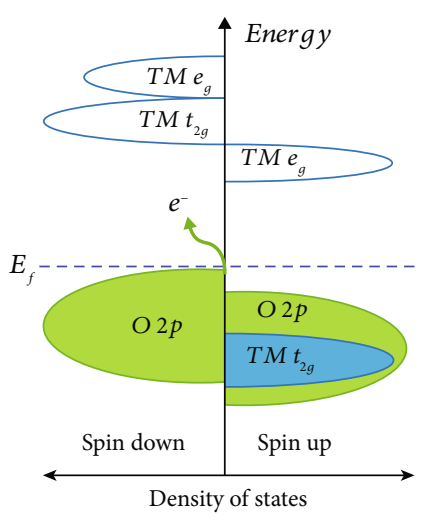

(b)

FIgURE 1: (a) Recent trend of cathode material for SIBs dealing anionic redox chemistry and (b) schematic pDOS diagram for oxygen redox reaction.

structure is smaller than those of P2 and P3, such that it is common to see more phase transitions in $\mathrm{O} 3$ layered compounds. Therefore, it is generally accepted that P2- and P3type layered cathode materials typically deliver higher capacity, reaching approximately $200 \mathrm{mAh} \mathrm{g}^{-1}$, with better capacity retention than $\mathrm{O} 3$ layered compounds, which usually have capacities of approximately $120 \mathrm{mAh} \mathrm{g}^{-1}$ based on the redox reaction of transition metal elements.

Indeed, the capacity contributed by transition metal elements is limited in those layered compounds. The anionic redox process enables delivery of additional capacity, such that sodium ions can be additionally de/intercalated fro$\mathrm{m} /$ into the structure; namely, the combination of cationic and anionic redox reactions provides more capacity. This type of chemistry has been demonstrated in Li-rich manganese oxide systems $\left(\mathrm{Li}_{2} \mathrm{MnO}_{3}\right.$ [7-9], $\mathrm{Li}_{1.2} T M_{0.8} \mathrm{O}_{2}$ [10-12], and their derivatives [13-16]) that have provided capacities to their theoretical limit. These anionic redox can contribute to additional capacity, thereby increasing the specific energy density of the battery. This phenomenon has been observed in overstoichiometric lithium compounds, where lithium partially replaces transition metals (TMs) with typical feature of $\mathrm{Li}\left[\mathrm{Li}_{x} \mathrm{TM}_{1-x}\right] \mathrm{O}_{2}$ (TM: $\mathrm{Ni}, \mathrm{Co}, \mathrm{Fe}, \mathrm{Cu}$, etc.) [12-14] or $\mathrm{Li}_{1}$ ${ }_{+x} T M_{1-x} \mathrm{O}_{2}$ (TM: Ru and Ir) $[15,16]$. These materials provide a higher capacity than the theoretical value obtained from a redox pair TM. The former compounds based on $3 d$ metal $(\mathrm{Mn})$ are of interest due to their high capacity in excess of $250 \mathrm{mAh}$ (g-oxide $)^{-1}$. However, they still suffer from voltage drop and irreversible capacity loss associated with migration of cations in the crystal lattice and the release of oxygen during the charging process. The latter compounds based on $4 d$ $(\mathrm{Ru})$ and $5 d(\mathrm{Ir})$ metals have attracted considerable attention from a fundamental and theoretical point of view. It was found that the transition from $3 d(\mathrm{Mn})$ to $4 d(\mathrm{Ru})$ or $5 d$ (Ir) metals can increase the covalence of $T M-O$ and stabilize oxygen-redox reactions. This higher covalence increases the structural rigidity and reduces the stress associated with the removal of lithium ions from the structure. This concept is also applicable to SIBs, which has triggered the intensive investigation of cathode materials from their synthesis to the elucidation of the mechanism of the anionic redox
(Figure 1(a)). During deintercalation of charge carriers, the Fermi level lowers to the top of $\mathrm{O} 2 p$ bands, spontaneously generating excess electrons accompanying deintercalation of charge carriers to prevent structural collapse, and vice versa during intercalation (Figure 1(b)). That is, electron transfer is solely contributed by the oxygen activity, of which the resulting TM-O distance becomes shortened as a result of the oxidation of oxygen. Therefore, additional capacity is delivered along with the contribution by the redox reaction of transition metal elements. Electrochemical oxidation of anions is more facile than the reaction during reduction, and this approach can balance the abnormal CE during the first cycle, potentially obviating the need for presodiation or additives to compensate for the low first charge capacity for P2 and P3 layered compounds.

The selection of elements in transition metal layers is of great importance in improving the reversibility and controlling the operation voltage of the anionic redox reaction, namely, $\mathrm{Na}_{x}\left[\mathrm{~A}_{y} T M_{1-y}\right] \mathrm{O}_{2}$ (A: $\mathrm{Li}$ [17-29], $\mathrm{Na}$ [30-45], $\mathrm{Mg}$ [46-56], $\mathrm{Zn}[57-60], \mathrm{Ni}$ [61-68], $\mathrm{Cu}[67-70], \mathrm{Fe}[71,72]$ or vacancy [54, 55, 73-81]; TM: Mn [17-29, 46-70, 73-85], Ru $[30-42,85,86]$, or $\operatorname{Ir}[43-45,87])$. There are widely accepted requirements for oxygen-redox reaction, namely, a local $\mathrm{Na}$ $\mathrm{O}-\mathrm{A}$ coordination medium for the redox activation of oxygen in layered $\mathrm{Na}_{x}[\mathrm{ATM}] \mathrm{O}_{2}$ for $\mathrm{P} 2, \mathrm{P} 3$, and O3-type layered compounds. The presence of the Na-O-A configuration triggers anionic reactions that depend on structures through the irreversible release of $\mathrm{O}_{2}$, reversible redox process, and hysteresis process. The migration of these $\mathrm{Li}$ and $\mathrm{Na}$ in the transition metal layers to the Na layers causes the formation of a lone pair of electrons in the $\mathrm{O} 2 p$ orbital, so that the high density of state energy for the oxygen allows the oxidation of oxygen although the reaction is kinetically slow. Herein, we review the current status of research and remaining challenges for the anionic reaction and associated mechanisms for different structures and elements of cathode materials for SIBs.

\section{Sodium-Deficient Layered Structures}

Sodium-deficient layered compounds, $\mathrm{Na}_{x}\left[\mathrm{~A}_{y} T M_{1-y}\right] \mathrm{O}_{2}$ (A: $\mathrm{Li}$ [17-29], Mg [46-56], Zn [57-60], Ni [61-66], or $\mathrm{Cu}$ 


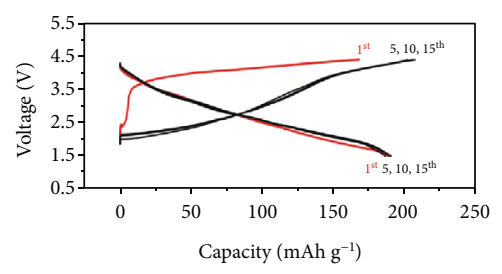

(a)

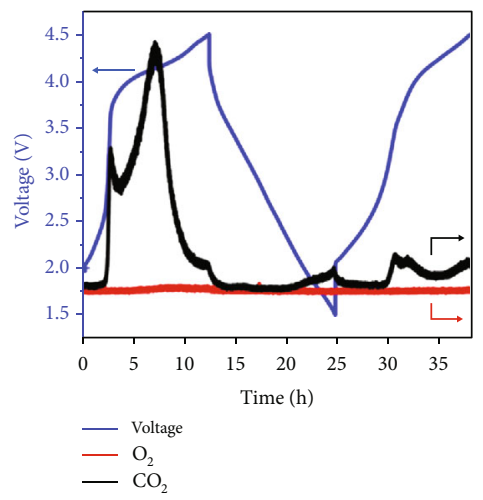

(d)

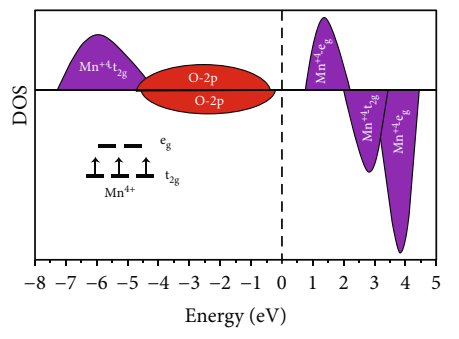

(b)

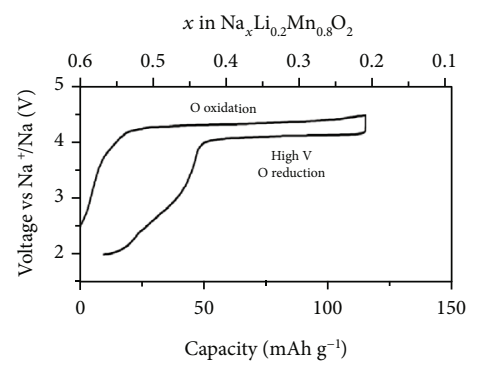

(e)

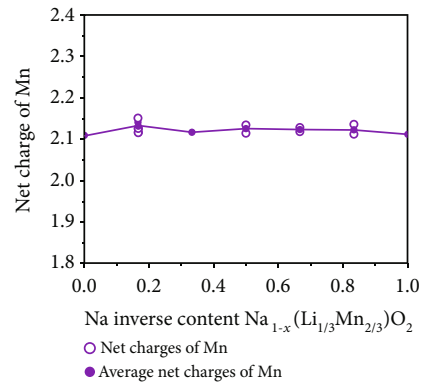

(c)

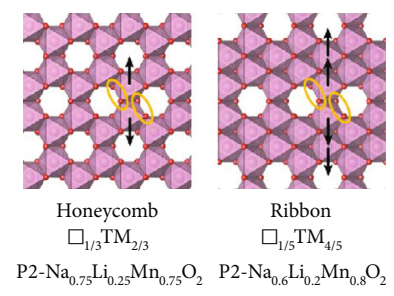

(f)

Figure 2: (a) Initial charge and discharge curves of P2-type $\mathrm{Na}_{5 / 6}\left[\mathrm{Li}_{1 / 4} \mathrm{Mn}_{3 / 4}\right] \mathrm{O}_{2}$ cycled at a rate of $10 \mathrm{~mA} \mathrm{~g}^{-1}$ in a voltage range of 2-4.8 $\mathrm{V}$ in a $\mathrm{Na}$ cell (reprinted with permission from ref. [17], Copyright 2014 WILEY-VCH Verlag GmbH \& Co. KGaA, Weinheim), (b) schematic projected density of state of P2-type $\mathrm{Na}_{0.6}\left[\mathrm{Li}_{0.2} \mathrm{Mn}_{0.8}\right] \mathrm{O}_{2}$ (reprinted with permission from ref. [21], Copyright 2016 American Chemical Society), (c) average net charges obtained from the Bader charge calculation for $\mathrm{Mn}$ and its fitted values as a function of inverse $\mathrm{Na}$ content (x) in P2-type $\mathrm{Na}_{0.6}\left[\mathrm{Li}_{0.2} \mathrm{Mn}_{0.8}\right] \mathrm{O}_{2}$ (reprinted with permission from ref. [25], Copyright 2020 WILEY-VCH Verlag GmbH \& Co. $\mathrm{KGaA}$, Weinheim), (d) gas evolution from P2-type $\mathrm{Na}_{0.67}\left[\mathrm{Li}_{0.22} \mathrm{Mn}_{0.78}\right] \mathrm{O}_{2}$ for the first cycle at $\mathrm{C} / 20$ (reprinted with permission from ref. [21], Copyright 2016 American Chemical Society), (e) the first charge and discharge profile of ordered superstructure P2-type $\mathrm{Na}_{0.6}\left[\mathrm{Li}_{0.2} \mathrm{Mn}_{0.8}\right] \mathrm{O}_{2}$, and (f) dependence of oxygen redox stability on superstructure (reproduced with permission from ref. [28], Copyright 2020 The Royal Society of Chemistry).

[67-70], $0.4 \leq x \leq 0.8, y \leq 1 / 3)$, known as P2 and P3 types, typically deliver high discharge capacities of $160-$ $220 \mathrm{mAh}^{-1}$. The prismatic environment for sodium ions enables maintenance of the large interlayer distances during $\mathrm{de} /$ sodiation, which is beneficial for facile diffusion of sodium ions and smooth phase transitions. However, in addition to the aforementioned merits, the sodium deficiency in the compounds results in small charge capacities (80$150 \mathrm{mAhg}^{-1}$ ), thereby resulting in an abnormal CE in the first cycle that should be circumvented for their adoption in practical applications. This concern can be resolved through the additional charge capacity derived by oxidation of lattice oxygen in the structure of layered P2 and P3 compounds.

2.1. P2-Type Layered Compounds. The P2-type layered structure is stabilized in forms of $\mathrm{Na}_{x}\left[\mathrm{~A}_{y} T M_{1-y}\right] \mathrm{O}_{2}(0.4 \leq x \leq 0.8)$, for which a third of the TM layers can be filled by mono- or divalent elements such as $\mathrm{Li}$ [17-29], $\mathrm{Mg}$ [46-56], and $\mathrm{Zn}$ [57-59] to induce an average oxidation state of $\mathrm{Mn}$ of $4+$. Hence, the extraction of sodium ions in the structure is not theoretically possible because of the difficulty of the oxidation of $\mathrm{Mn}^{4+}$ to higher valence states in an octahedral environment, in which the electrolyte does not decompose. In contrast, the divalent $\mathrm{Ni}$ and $\mathrm{Cu}$ participate in the redox process, which, in turn, provides additional capacity together with the oxygen redox process. This chapter discusses the effects of those substituents on the operation voltage, capacity, and related oxygen redox mechanism.

2.1.1. $\mathrm{P} 2 \mathrm{Na} a_{x}\left[\mathrm{Li}_{y} \mathrm{Mn}_{1-y}\right] \mathrm{O}_{2}$. The presence of the low-valence metal, $\mathrm{Li}$, in the TM layers is intriguing because more sodium can be adopted in the Na layers for charge compensation while maintaining the Mn oxidation state of $4+$. The first attempt was made by Yabuuchi and coworkers [17] for P2 $\mathrm{Na}_{5 / 6}\left[\mathrm{Li}_{1 / 4} \mathrm{Mn}_{3 / 4}\right] \mathrm{O}_{2}$ with a valence of $\mathrm{Mn}^{3.89+}$ (Figure 2(a)). The large amount of sodium was beneficial for the delivery of a high charge capacity, as P2-type cathode materials always suffer from a small charge capacity compared with the discharge value. The delivered capacity was determined by the oxidation state of $\mathrm{Mn}$, such that the $\mathrm{Na}_{5 / 6}\left[\mathrm{Li}_{1 / 4} \mathrm{Mn}_{3 / 4}\right] \mathrm{O}_{2}$ should have delivered a small charge capacity, assuming the oxidation of $\mathrm{Mn}^{3+}$ to $\mathrm{Mn}^{4+}$. The delivered first charge capacity was intriguingly high (over $170 \mathrm{mAh} \mathrm{g}^{-1}$ ) and accompanied by the partial formation of an O2-like P2 phase with a short interlayer distance, which could not explain the capacity by the cationic redox process because the oxidation of $\mathrm{Mn}^{4+}$ to $\mathrm{Mn}^{5+}$ does not likely occur in an octahedral environment. The resulting discharge 
capacity was also sufficiently high (approximately $200 \mathrm{mAh} \mathrm{g}^{-1}$ ) and was retainable with cycling. The authors proposed that partial oxygen loss from the lattice and inplane rearrangement by partial lithium extraction from the $T M$ layers activates the inactive tetravalent $\mathrm{Mn}$ to deliver high capacity. The authors also claimed that the $\mathrm{Li}$ in the $T M$ layers is responsible for the increased operation voltage compared with that of $\mathrm{Na}_{2 / 3} \mathrm{MnO}_{2}$. Later work by de la Llave and coworkers [21] explored the origins of the good electrode performance of $\mathrm{P} 2 \mathrm{Na}_{0.6}\left[\mathrm{Li}_{0.2} \mathrm{Mn}_{0.8}\right] \mathrm{O}_{2}$, which delivered a capacity of $\sim 190 \mathrm{mAh} \mathrm{g}^{-1}$. Their thermodynamic investigation demonstrated an energy state of oxygen located close to the Fermi level, which enabled oxidation of oxygen as sodium was extracted from the layered structure (Figure 2(b)). Yabuuchi et al. [17] proposed that lithium from the TM layers migrates toward the sodium layer when the octahedral environment is present at a highly desodiated state such as the $\mathrm{O} 2$ or OP4 phase. In this state, the density of states for $\mathrm{O} 2 p$ was located at a higher energy state than that for $\mathrm{Mn}^{4+} 3 d$ [25]; however, the net charge of Mn did not vary during the extraction of sodium ions in the structure (Figure 2(c)). In addition, oxygen was not released from the oxide lattice as the oxidation of oxygen progressed (Figure 2(d)). The continuous reduction of the $a$-axis parameter was also indicative of the gradual oxidation from $\mathrm{O}^{2-}$ to $\mathrm{O}^{n-}(n<2)$ during charge, compensating for the charge imbalance occurring in $\mathrm{Mn}^{4+}$. $\mathrm{Li}$ et al. [24] observed the migration of lithium using NMR in $\mathrm{Na}_{0.72}\left[\mathrm{Li}_{0.24} \mathrm{Mn}_{0.76}\right] \mathrm{O}_{2}$; however, the movement of lithium was suppressed by the reinforced bond in the structure provided by $\mathrm{Ti}^{4+} \mathrm{O}_{2}$ in $\mathrm{Ti}$ substituted $\mathrm{Na}_{0.72}\left[\mathrm{Li}_{0.24} \mathrm{Ti}_{0.10} \mathrm{Mn}_{0.66}\right] \mathrm{O}_{2}$. The improved structural stability enabled the retention of high capacity for cycling. A similar effect was observed in a F-doped system, P2 $\mathrm{Na}_{0.65}\left[\mathrm{Li}_{0.22} \mathrm{Mn}_{0.78}\right] \mathrm{O}_{1.99} \mathrm{~F}_{0.01}$ [20]. However, the aforementioned $\mathrm{P} 2 \mathrm{Na}_{x}\left[\mathrm{Li}_{y} \mathrm{Mn}_{1-y}\right] \mathrm{O}_{2}$ compounds exhibited hysteresis between charge and discharge, as evident in Figure 2(a).

House and coworkers [27] found that the migration of lithium causes in-plane migration of manganese in the structure on charge, such that the lithium in the Na layers moves back to different sites of the TM layers. This disordered arrangement of $\mathrm{Li}$ and $\mathrm{Mn}$ in the structure is thought to be one of the reasons for the hysteresis in the layered P2 $\mathrm{Na}_{x}[-$ $\left.\mathrm{Li}_{y} \mathrm{Mn}_{1-y}\right] \mathrm{O}_{2}$ compounds with honeycomb structure (Figure 2(a)). They also compared the hysteresis using superstructured $\mathrm{P} 2 \mathrm{Na}_{0.6}\left[\mathrm{Li}_{0.2} \mathrm{Mn}_{0.8}\right] \mathrm{O}_{2}$ (Figure 2(e)). It is worth mentioning that a flat voltage plateau, induced by the $\mathrm{O}^{2-1 n-}$ redox pair at $\sim 4.1 \mathrm{~V}$, was observed during charge and discharge for the superstructured $\mathrm{P} 2 \mathrm{Na}_{0.6}\left[\mathrm{Li}_{0.2} \mathrm{Mn}_{0.8}\right] \mathrm{O}_{2}$. In this case, $\mathrm{Mn}$ migration is suppressed although lithium moves to the Na layers (Figure 2(f)); the improved in-plane ordering is responsible for the reversible flat plateau with high operation voltage on charge and discharge. Notwithstanding, the behavior became less evident as repetitive lithium migration and recovery progressed because of the in-plane disorder in the superstructure.

This series of cathode materials utilize less than 36\% oxygen in the lattice, implying that most cases have a high average oxidation state of Mn of higher than 3.5+. Because Jahn-
Teller distortion is predominant in $\mathrm{Mn}^{3+} \mathrm{O}_{6}$ octahedra, it is mainly observed in the deeply discharged state, which usually accompanies the formation of the P'2 structure. However, the aforementioned $\mathrm{P} 2 \mathrm{Na}_{x}\left[\mathrm{Li}_{y} \mathrm{Mn}_{1-y}\right] \mathrm{O}_{2}$ compounds first reduce the oxidized oxygen $\left(\mathrm{O}^{n-}\right)$ to $\mathrm{O}^{2-}$ in the high-voltage region, after which $\mathrm{Mn}$ initiates its reduction from $\mathrm{Mn}^{4+}$ to $\mathrm{Mn}^{3+}$ until the end of discharge. Through this process, the average oxidation state of $\mathrm{Mn}$ is usually higher than 3.5; therefore, the Jahn-Teller distortion appears less dominant at the end of sodiation, $\mathrm{Na}_{x}\left[\mathrm{Li}_{y} T M_{1-y}\right] \mathrm{O}_{2}(0.9 \leq x \leq 1, y \leq 1 / 3)$, without notable formation of the P2 structure, which is affected by the presence of Jahn-Teller distortion.

Cao et al. [29] stabilized the oxygen-redox chemistry in P2 $\mathrm{Na}_{0.66}\left[\mathrm{Li}_{0.22} \mathrm{Ru}_{0.78}\right] \mathrm{O}_{2}$. Lowering of the transition metal $d$ energy is possible using $4 d$ or $5 d$ elements such as Ru and Ir; hence, the oxygen redox can be active in the nonbonding state of $\mathrm{O} 2 p . \mathrm{Ru}^{4+}$ was first oxidized to $\mathrm{Ru}^{5+}$, and further desodiation led to oxidation of oxygen, resulting in additional capacity but no evolution of $\mathrm{O}_{2}$ gas from the crystal structure. The series of reactions resulted in a discharge capacity of $\sim 160 \mathrm{mAh} \mathrm{g}^{-1}$. As more covalent character is seen for the elements on the right side of the periodic table, the migration of $\mathrm{Li}$ to the Na layers was suppressed even though the oxygen redox was dominant in the Z-phase region, like the $\mathrm{O} 2$ or OP4 phase that provides octahedral coordinates, for the highly desodiated state. The suppression of lithium migration and lack of $\mathrm{O}_{2}$ release enabled reversible electrochemical reaction for 500 cycles.

2.1.2. $\mathrm{P} 2 \mathrm{Na} a_{x}\left[\mathrm{Mg}_{y} M n_{1-y}\right] \mathrm{O}_{2}$. The importance of the $\mathrm{Na}^{+}-$ $\mathrm{O}(2 p)-\mathrm{Li}^{+}$interaction for progression of the oxygen redox in the lattice of $\mathrm{P} 2 \mathrm{Na}_{x}\left[\mathrm{Li}_{y} \mathrm{Mn}_{1-y}\right] \mathrm{O}_{2}$ was explained in the previous section. Yabuuchi et al. [46] proposed the highly reversible electrochemical activity of P2 $\mathrm{Na}_{2 / 3}\left[\mathrm{Mg}_{0.28} \mathrm{Mn}_{0.72}\right] \mathrm{O}_{2}$, which does not include vacancies in the TM layers and for which $\mathrm{Mn}$ has a valence state of $\sim 3.85^{+}$. It was proposed that $0.15 \mathrm{e}^{-}$could be used to induce the change of $\mathrm{Mn}$ to $\mathrm{Mn}^{4+}$ during charge, which may result in $\sim 40 \mathrm{mAh} \mathrm{g}^{-1}$ of capacity assuming a $\mathrm{Mn}^{3+/ 4+}$ redox. Surprisingly, the compound delivered a charge capacity of $\sim 150 \mathrm{mAh}$ with a plateau over $4.1 \mathrm{~V}$ undergoing a phase transition from $\mathrm{P} 2$ to $\mathrm{O} 2$, whereas the recovery on discharge was $\sim 210 \mathrm{mAh} \mathrm{g}^{-1}$ even though there was a gradual decay in the capacity with cycling (Figure 3(a)). They reasoned that oxygen-related activity or the partial loss of oxygen was associated with the activity of the compound, although a small portion derived from the oxidation of $\mathrm{Mn}^{3+}$ to $\mathrm{Mn}^{4+}$ $(\sim 15 \%)$ was available for the first charge capacity. Clement et al. [47] observed structural stability in $\mathrm{Na}_{x}\left[\mathrm{Mg}_{y} \mathrm{Mn}_{1-y}\right] \mathrm{O}_{2}$ $(y=0-0.1)$, which led to the suppression of the Jahn-Teller distortion by $\mathrm{Mn}^{3+}$ and potential $\mathrm{Mn}^{3+} / \mathrm{Mn}^{4+}$ ordering in the structure. Later, Maitra et al. [48] confirmed the availability of the oxygen-redox chemistry in $\mathrm{P} 2 \mathrm{Na}_{2 / 3}\left[\mathrm{Mg}_{0.28} \mathrm{Mn}_{0.72}\right] \mathrm{O}_{2}$, which does not require excess alkali metal such as lithium in the TM layers of the compound. According to their combined studies of O K-edge X-ray absorption (XAS) and resonant inelastic X-ray scattering (RIXS), the voltage plateau above $4.1 \mathrm{~V}$, with the phase transition from $\mathrm{P} 2$ to $\mathrm{O} 2$ or OP4, can be attributed to the reaction of the electron- 


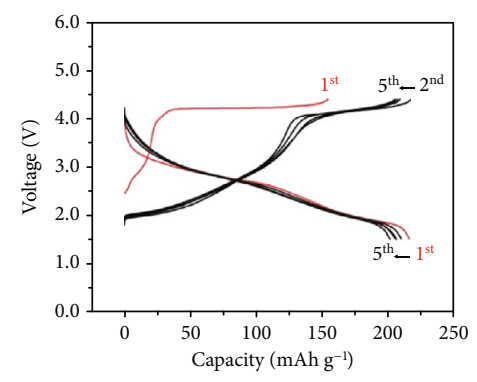

(a)

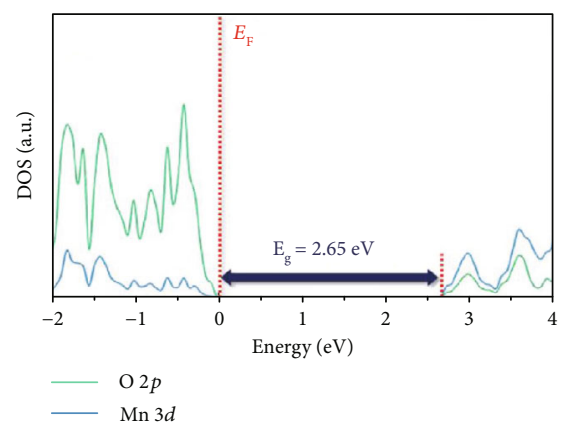

(b)

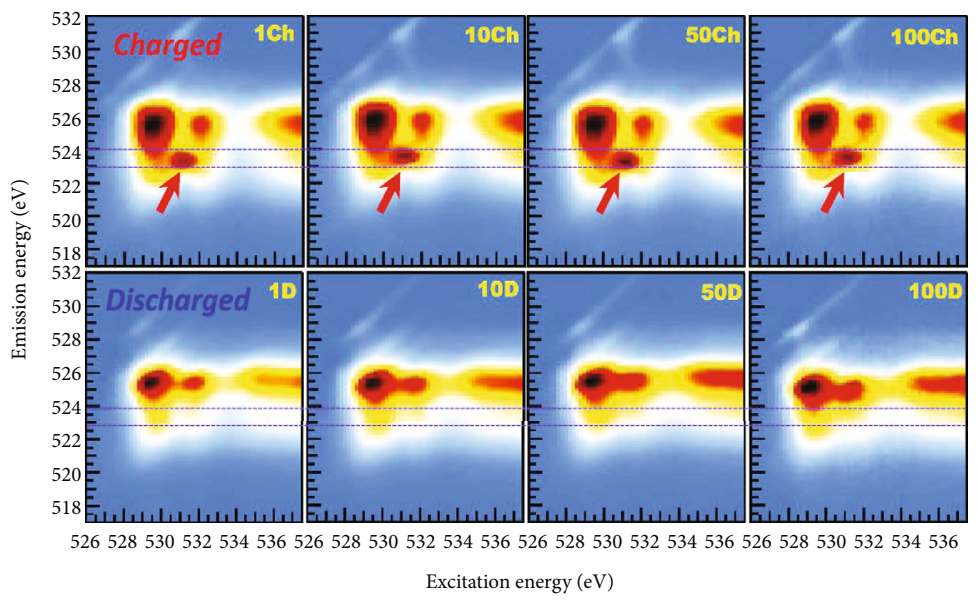

(d)

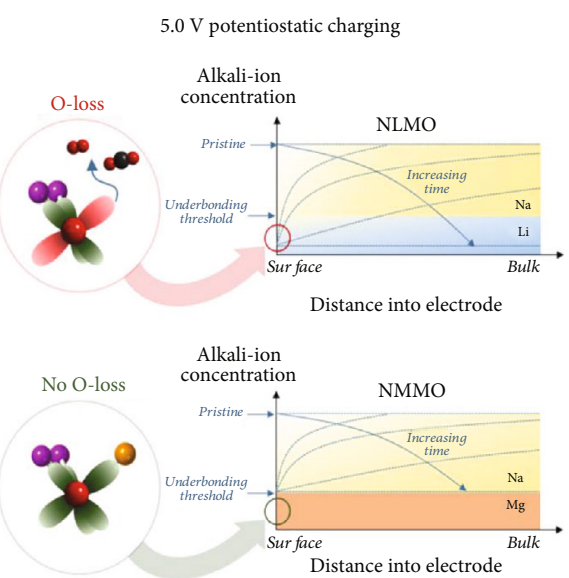

(c)

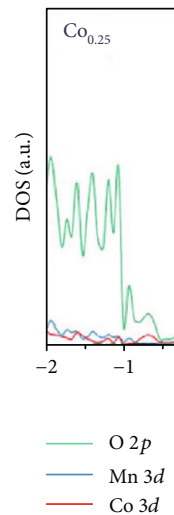

(e)

FIGURE 3: (a) Initial charge and discharge profiles of P2-type $\mathrm{Na}_{2 / 3}\left[\mathrm{Mg}_{0.28} \mathrm{Mn}_{0.72}\right] \mathrm{O}_{2}$ tested at $10 \mathrm{~mA} \mathrm{~g}^{-1}$ (reproduced with permission from Ref. [29], Copyright 2014 The Royal Society of Chemistry); (b) projected density of state showing oxygen states at the Fermi level for P2-type $\mathrm{Na}_{0.5}\left[\mathrm{Mg}_{0.25} \mathrm{Mn}_{0.75}\right] \mathrm{O}_{2}$ (reprinted with permission from Ref. [51] Copyright 2020 WILEY-VCH Verlag GmbH \& Co. KGaA, Weinheim); (c) the concentration profiles of alkali ions $\mathrm{Li}, \mathrm{Na}$, and $\mathrm{Mg}$ within P2-type $\mathrm{Na}_{0.78}\left[\mathrm{Li}_{0.25} \mathrm{Mn}_{0.75}\right] \mathrm{O}_{2}$ (top) and $\mathrm{P} 2$-type $\mathrm{Na}_{0.67}\left[\mathrm{Mg}_{0.28} \mathrm{Mn}_{0.72}\right] \mathrm{O}_{2}$ (bottom) electrode particles at $5 \mathrm{~V}$ charging condition (reprinted with permission from Ref. [52], Copyright (2016) American Chemical Society); (d) O-K mRIXS images charged (top) and discharged (bottom) P2-type $\mathrm{Na}_{2 / 3}\left[\mathrm{Mg}_{1 / 3} \mathrm{Mn}_{2 / 3}\right] \mathrm{O}_{2}$ electrodes after the 1st, 10th, 50th, and 100th cycles (red arrow: oxidized oxygen features in charged states) (reprinted with permission from Ref. [83] Copyright 2020 Frontiers Media S.A.); (e) projected density of state of charged P2-type $\mathrm{Na}_{0.5}\left[\mathrm{Mg}_{0.25} \mathrm{Mn}_{0.5} \mathrm{Co}_{0.25}\right]_{2}$ (reprinted with permission from Ref. [35] Copyright 2019 WILEY-VCH Verlag GmbH \& Co. KGaA, Weinheim).

deficient oxide ion (oxygen hole) in the $2 p$ orbital interacting with the $\mathrm{Mg}^{2+} 3 s$ and $\mathrm{Mn}^{4+} 3 d$ orbitals. Charge compensation was achieved via this reaction, resulting in the extraction of sodium ions from $\mathrm{Na}_{2 / 3}\left[\mathrm{Mg}_{0.28} \mathrm{Mn}_{0.72}\right] \mathrm{O}_{2}$. It is interesting that the $3 s$ state of $\mathrm{Mg}^{2+}$ is higher than the $2 p$ state of oxygen according to the DFT calculation, implying a weak ionic bond of $\mathrm{Mg}-\mathrm{O}$ that is similar to that of $\mathrm{Li}-\mathrm{O}$ in $\mathrm{Na}_{x}[-$ $\left.\mathrm{Li}_{y} \mathrm{Mn}_{1-y}\right] \mathrm{O}_{2}$ (Section 2.1.1). This finding suggests the placement of the $\mathrm{O} 2 p$ orbital at the top of the valence band (Figure 3(b)). $\mathrm{Mg}^{2+}$ did not migrate, which is different from the $\mathrm{Li}^{+}$migration in $\mathrm{Na}_{x}\left[\mathrm{Li}_{y} \mathrm{Mn}_{1-y}\right] \mathrm{O}_{2}$, and $\mathrm{O}$ was not released during the electrochemical reaction [48, 53]. House et al. [52] confirmed the origin of oxygen loss through comparison of P2 $\mathrm{Na}_{2 / 3}\left[\mathrm{Mg}_{0.28} \mathrm{Mn}_{0.72}\right] \mathrm{O}_{2}$ and P2 $\mathrm{Na}_{0.78}\left[\mathrm{Li}_{0.25} \mathrm{Mn}_{0.75}\right] \mathrm{O}_{2}$. Even when $\mathrm{Na}_{2 / 3}\left[\mathrm{Mg}_{0.28} \mathrm{Mn}_{0.72}\right] \mathrm{O}_{2}$ was charged to $5 \mathrm{~V}$, there was no indication of oxygen evolution nor $\mathrm{Mg}$ migration. In addition, charging of
$\mathrm{Na}_{0.78}\left[\mathrm{Li}_{0.25} \mathrm{Mn}_{0.75}\right] \mathrm{O}_{2}$ to over $4.5 \mathrm{~V}$ resulted in a clear decrease in the lithium concentration in the structure (Figure 3(c)). Hence, the authors proposed that lithium migration results in oxygen underbonding in the lattice, which triggers oxygen loss together with lithium loss from the surface of $\mathrm{Na}_{0.78}\left[\mathrm{Li}_{0.25} \mathrm{Mn}_{0.75}\right] \mathrm{O}_{2}$. This behavior is related to the stronger bond of $\mathrm{Mg}-\mathrm{O}$ relative to that of $\mathrm{Li}-\mathrm{O}$, enabling oxygen-redox activity without excess alkali metal ions in the TM layers. Dai et al. [82] verified the availability of the oxygen redox of $\mathrm{Na}_{2 / 3}\left[\mathrm{Mg}_{1 / 3} \mathrm{Mn}_{2 / 3}\right] \mathrm{O}_{2}$ throughout cycling using mRIXS (m: mapping) (Figure 3(d)). The emission energy emerging at $523.7 \mathrm{eV}$ repeatedly appeared at different charge ends, such as the 1st, 10th, 50th, and 100th cycles, whereas the signal was not visible at the end of discharge. This finding indicates that the obtained capacity can be attributed to both cationic and anionic redox processes during cycling. 
The presence of vacancies $\square$ in TM layers also helps accelerate the oxygen-redox reaction by forming $\mathrm{Na}-\mathrm{O}-\mathrm{Mg}$ and $\mathrm{Na}-\mathrm{O}-\square_{\mathrm{Mg}}$ configurations $[54,55]$. Interestingly, the Mg-deficient P2 $\mathrm{Na}_{0.63}\left[\mathrm{Mg}_{0.143} \mathrm{Mn}_{0.820} \square_{\mathrm{Mg} 0.036}\right] \mathrm{O}_{2}$ underwent a single-phase reaction during de-/sodiation [55], without showing a phase transition to the $\mathrm{O} 2$ or OP4 phase. The vacancy in $\mathrm{Na}_{0.63}\left[\mathrm{Mg}_{0.143} \mathrm{Mn}_{0.820} \square_{\mathrm{Mg} 0.036}\right] \mathrm{O}_{2}$ slightly lowered the average oxidation state of $\mathrm{Mn}$ compared with that of the vacancy-free $\mathrm{Na}_{0.72}\left[\mathrm{Mg}_{0.31} \mathrm{Mn}_{0.69}\right] \mathrm{O}_{2}$. In addition, it is interesting to see the additional voltage plateau over $4 \mathrm{~V}$ induced by the oxidation of oxygen in the lattice, even though the P2 phase was dominant in the plateau region. Their operando XRD study confirmed that the variation in the $a$-axis observed for $\mathrm{Na}_{0.63}\left[\mathrm{Mg}_{0.143} \mathrm{Mn}_{0.820} \square_{\mathrm{Mg}_{0.036}}\right] \mathrm{O}_{2}$ occurred after the reaction associated with the oxidation of $\mathrm{Mn}^{3+}$ to $\mathrm{Mn}^{4+}$. The same effect was observed in $\mathrm{Na}_{2 / 3}\left[\mathrm{Mg}_{1 / 9} \mathrm{Mn}_{7 / 9} \square_{\mathrm{Mg} 1 / 9}\right] \mathrm{O}_{2}$, with not only the absence of the phase transition but a higher capacity than that of the vacancy-free compound [55]. DFT calculation indicated that the oxygen close to the vacancies $\left(\mathrm{Na}-\mathrm{O}-\square_{\mathrm{Mg}}\right)$ provides more charge than the oxygen coordinated with $\mathrm{Mg}(\mathrm{Na}-\mathrm{O}-$ $\mathrm{Mg}$ ) on charge, resulting in more charge compensation with the presence of vacancies that induce the lower-level voltage plateau for the oxygen reaction. Therefore, these properties were responsible for the increased capacity with improved reversibility in these vacancy-containing compounds [51].

Efforts have been made to improve the sluggish oxygenredox reaction in terms of the operation voltage, capacity retention, and rate capability by introducing transition metals (Ni [51] and Co [51]). Tapia-Ruiz et al. [49] demonstrated that increased operation voltage was achieved with partial substitution of $\mathrm{Mg}^{2+}$ by $\mathrm{Ni}^{2+}, \mathrm{Na}_{2 / 3}\left[\mathrm{Mg}_{1 / 3-}\right.$ $\left.{ }_{x} \mathrm{Ni}_{x} \mathrm{Mn}_{2 / 3}\right] \mathrm{O}_{2}(0 \leq x \leq 0.2)$, with the added $\mathrm{Ni}$ resulting in the suppression of the $\mathrm{P} 2$ to $\mathrm{O} 2$ phase transition. Kim et al. [51] utilized the nature of the overlapping of density of states between cobalt $3 d$ and oxygen $2 p$ observed in $\mathrm{LiCoO}_{2}$, facilitating electron transfer. The effect of $\mathrm{Co}$ in $\mathrm{Na}_{0.6}\left[\mathrm{Mg}_{0.2-}\right.$ $\mathrm{Co}_{0.2} \mathrm{Mn}_{0.6} \mathrm{O}_{2}$ resulted in not only a high discharge capacity, $214 \mathrm{mAh} \mathrm{g}^{-1}$, including the capacity provided by the oxygen redox, but also good capacity retention for 1000 cycles at a rate of $5 \mathrm{C}\left(1.82 \mathrm{Ag}^{-1}\right)$. Their pDOS demonstrated the effect of $\mathrm{Co}$, which sufficiently lowered the bandgap energy to 0.61 from $2.65 \mathrm{eV}$, and the high DOS energy of oxygen relative to that of $\mathrm{Mn}$ and Co (Figure 3(e)). However, further investigation of these compounds is suggested to minimize the polarization during the oxygen redox process observed in the OP4-phase region.

2.1.3. $\mathrm{P} 2 \mathrm{Na}_{x}\left[\mathrm{Zn}_{y} \mathrm{Mn}_{1-y}\right] \mathrm{O}_{2}$. The potential use of $\mathrm{Zn}$ is also of interest because of its high Pauling electronegativity, 1.65, which is higher than that of $\mathrm{Mg}$ (1.33) that has no $d$ orbital. Konarov et al. [57] compared the pDOS O $2 p$ orbitals for $\mathrm{Na}_{0.5} \mathrm{MnO}_{2}$ and $\mathrm{Na}_{0.5}\left[\mathrm{Zn}_{0.25} \mathrm{Mn}_{0.75}\right] \mathrm{O}_{2}$, with the latter having a large charge density between -1 and $0 \mathrm{eV}$ for oxygen owing to the existence of the $\mathrm{Na}-\mathrm{O}-\mathrm{Zn}$ configuration. The desodiated state of $\mathrm{Na}_{0}\left[\mathrm{Zn}_{0.25} \mathrm{Mn}_{0.75}\right] \mathrm{O}_{2}$ contained an unoccupied state of the $\mathrm{O} 2 p$ orbital above the Fermi energy (Figure 4(a)). Unlike $\mathrm{Li}-\mathrm{O}$ and $\mathrm{Mg}-\mathrm{O}$ bonding, which are ionic, the high electronegativity in $\mathrm{Na}-\mathrm{O}-\mathrm{Zn}$ bonding is likely to induce covalence in the structure. Zn migration or oxygen loss was not observed during de/sodiation, which may result in an increase in the $\mathrm{Na}-\mathrm{O}-\mathrm{Zn}$ bonding, resulting in an unpaired electron that can trigger $\mathrm{O}^{2-/ 1-}$ redox, which agrees with the results proposed by Bai et al. [58] and Zheng et al. [59]. Although a strong covalence was expected, the phase transition from P2 to OP4 was inevitable in the highvoltage region. Importantly, the average oxidation $\mathrm{Mn}$ was higher than $3.5^{+}$, which can effectively minimize the cooperative Jahn-Teller effect during cycling. These intrinsic properties resulted in good capacity retention upon cycling (Figure 4(b)); however, further elaboration is required to not only improve the rate capacity but also raise the operation voltage. Konarov et al. [60] circumvented these demerits of P2 $\mathrm{Na}_{x}\left[\mathrm{Zn}_{y} \mathrm{Mn}_{1-y}\right] \mathrm{O}_{2}$ by replacing half of the $\mathrm{Zn}^{2+}$ with $\mathrm{Ni}^{2+}$. The observed average discharge voltage was approximately $3.5 \mathrm{~V}$, and their $\mathrm{Na}_{2 / 3}\left[\left(\mathrm{Ni}_{0.5} \mathrm{Zn}_{0.5}\right)_{0.3} \mathrm{Mn}_{0.7}\right] \mathrm{O}_{2}$ was able to deliver a capacity of over $70 \mathrm{mAhg}^{-1}$ even at a rate of $10 \mathrm{C}$ (Figure 4(c)). Such improvement was attributed to the presence of the Ni element, which provided improved electrical conductivity and activity of the $\mathrm{Ni}^{2+/ 4+}$ redox reaction.

2.1.4. P2 $\mathrm{Na}_{x}\left[\mathrm{~A}_{y} \mathrm{Mn}_{1-y}\right] \mathrm{O}_{2} \quad(\mathrm{~A}: \mathrm{Ni}, \mathrm{Cu}$, and $\mathrm{Fe}) . \quad \mathrm{P} 2$ $\mathrm{Na}_{2 / 3}\left[\mathrm{Ni}_{1 / 3} \mathrm{Mn}_{2 / 3}\right] \mathrm{O}_{2}$ is known to provide a reversible $\mathrm{Ni}^{2}$ ${ }^{+/ 4+}$ redox reaction with three voltage plateaus at 3.2, 3.6, and $4.1 \mathrm{~V}$, whereas the tetravalent $\mathrm{Mn}$ does not participate in the electrochemical reaction. The desodiation leads to the formation of the $\mathrm{O} 2$ phase accompanied by a large volume change of approximately $23 \%$ that induces cracking of particles; hence, the material suffers from severe capacity fade during cycling. Recently, this material was revisited to relate the high-voltage reaction occurring over $4.1 \mathrm{~V}$ to the oxygen-redox reaction [61-72]. Ma et al. [61] investigated $\mathrm{Na}_{0.78}\left[\mathrm{Ni}_{0.23} \mathrm{Mn}_{0.69}\right] \mathrm{O}_{2}$ with $7 \%$ vacancies in the $T M$ layers. The desodiation induced the oxidation of $\mathrm{Ni}^{2+}$ toward $\mathrm{Ni}^{4+}$, and the oxidation of oxygen was also confirmed by XAS when $\mathrm{Ni}$ was oxidized to $4^{+}$, which corresponds to the plateau seen over 4.1 V. Later, Cheng et al. [62] and Dai et al. [67] employed mRIX to confirm the oxygen activity in $\mathrm{Na}_{2 / 3}\left[\mathrm{Ni}_{1 / 3} \mathrm{Mn}_{2 / 3}\right] \mathrm{O}_{2}$. Similarly, the two-electron reaction was dominant for $\mathrm{Ni}$, whereas the upper voltage plateau over $4.1 \mathrm{~V}$ was mainly governed by the oxygen-redox reaction. The signature seen at $523 \mathrm{eV}$ in emission energy was not visible after discharge. Zuo et al. [66] proposed a possible process for the oxygen redox behavior using pDOS data. In the highly desodiated state, the energy of $\mathrm{O} 2 p$ in the $\mathrm{e}_{\mathrm{g}} *(\mathrm{Ni}-$ $\mathrm{O})$ becomes higher than that of $\mathrm{Ni} 3 d$, which triggers the oxygen-redox reaction. Zhang et al. [65] observed $\mathrm{O}_{2}$ release from the structure at the highly charge state, which produces a dense $\mathrm{Ni}_{2} \mathrm{Mn}_{2} \mathrm{O}_{7}$ layer on the outer surface of $\mathrm{Na}_{2 / 3}$. ${ }_{x}\left[\mathrm{Ni}_{1 / 3} \mathrm{Mn}_{2 / 3}\right] \mathrm{O}_{2}$. This, in turn, plays a role in impeding $\mathrm{Na}^{+}$ diffusion, causing irreversible capacity in the first cycle. They circumvented the $\mathrm{O}_{2}$ release by introducing a small amount of $\mathrm{Fe}^{3+}, \mathrm{Na}_{2 / 3}\left[\mathrm{Fe}_{2 / 9} \mathrm{Ni}_{2 / 9} \mathrm{Mn}_{5 / 9}\right] \mathrm{O}_{2}$ (Figure 4(d)), such that the first irreversible capacity was dramatically reduced to approximately $4 \%$. According to their thermodynamic calculation, such improvement was related to the redistribution of electrons in the $\mathrm{Fe}-\mathrm{O}-\mathrm{O}$ configuration, for which the energy of oxygen in the pDOS was above the Fermi energy level after 


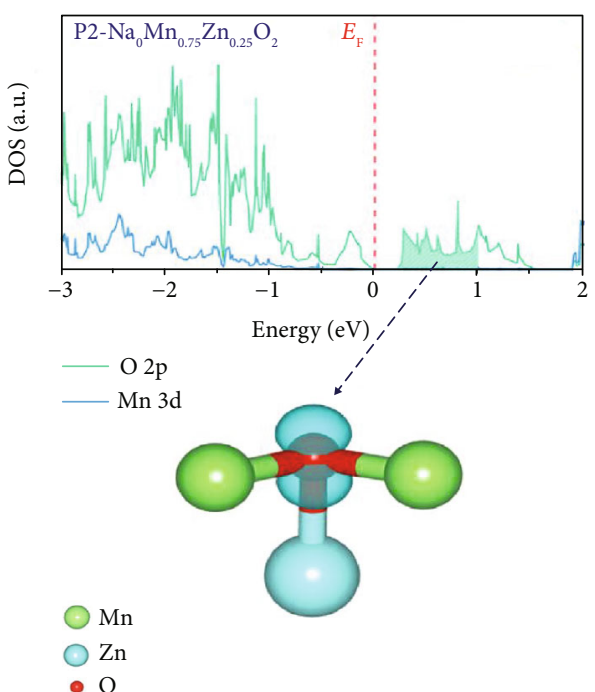

(a)

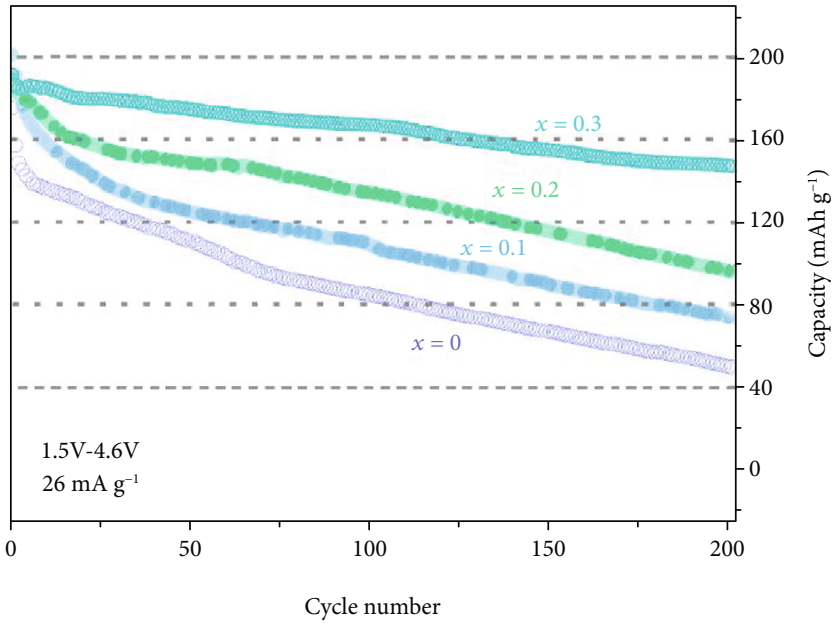

(b)

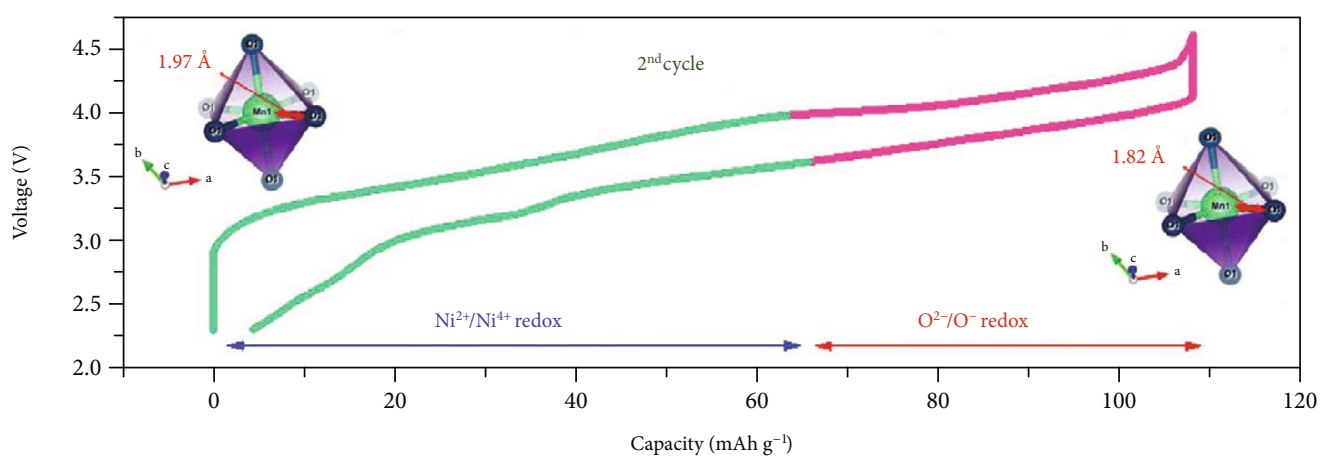

(c)

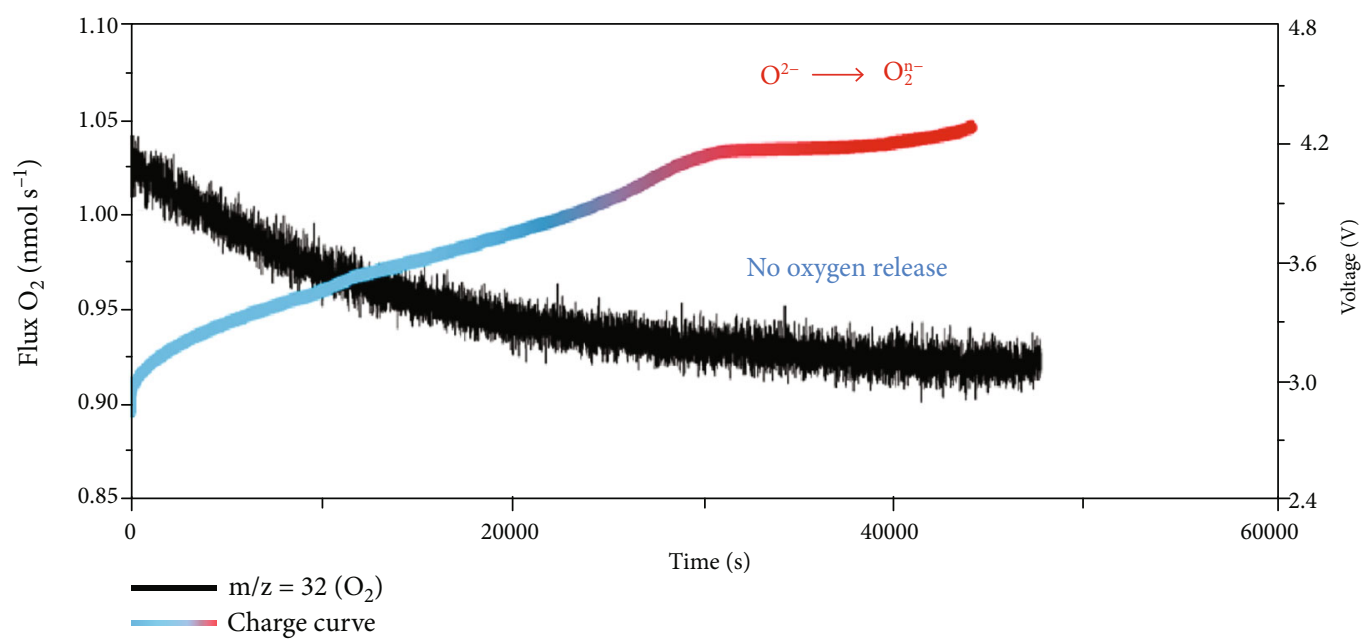

(d)

Figure 4: (a) Projected density of state for fully desodiated P2-type $\mathrm{Na}_{0}\left[\mathrm{Zn}_{0.25} \mathrm{Mn}_{0.75}\right] \mathrm{O}_{2}$ and spatial hole density (yellow) for $0 \mathrm{eV}<\mathrm{E}<1 \mathrm{eV}$ and (b) cyclability of P2-type $\mathrm{Na}_{2 / 3}\left[\mathrm{Zn}_{\mathrm{x}} \mathrm{Mn}_{1-\mathrm{x}}\right] \mathrm{O}_{2}(\mathrm{x}=0-0.3)$ (reprinted with permission from Ref. [57], Copyright 2019 Elsevier); (c) voltage profile and reaction mechanism of high voltage P2-type $\mathrm{Na}_{2 / 3}\left[\mathrm{Zn}_{0.125} \mathrm{Ni}_{0.125} \mathrm{Mn}_{0.7}\right] \mathrm{O}_{2}$ (reprinted with permission from Ref. [60], Copyright 2020 WILEY-VCH Verlag GmbH \& Co. KGaA, Weinheim); (d) DEMS analysis of oxygen evolution during the first charge for $\mathrm{Na}_{2 / 3}\left[\mathrm{Fe}_{2 / 9} \mathrm{Ni}_{2 / 9} \mathrm{Mn}_{5 / 9}\right] \mathrm{O}_{2}$ cathode (reprinted with permission from Ref. [65], Copyright (2020) American Chemical Society).

desodiation. This series of reactions is responsible for the suppression of oxygen release in the structure in the highly charged state. Co-doping of $\mathrm{Cu} / \mathrm{Mg}$ was also effective to retain the oxygen-redox reaction associated with $\mathrm{Ni}$ redox in $\mathrm{Na}_{0.67}\left[\mathrm{Ni}_{0.25} \mathrm{Mn}_{0.75}\right] \mathrm{O}_{2}$ [64]. Note that a prerequisite for oxygen redox is the unhybridized $\mathrm{O} 2 p$ orbital that is 


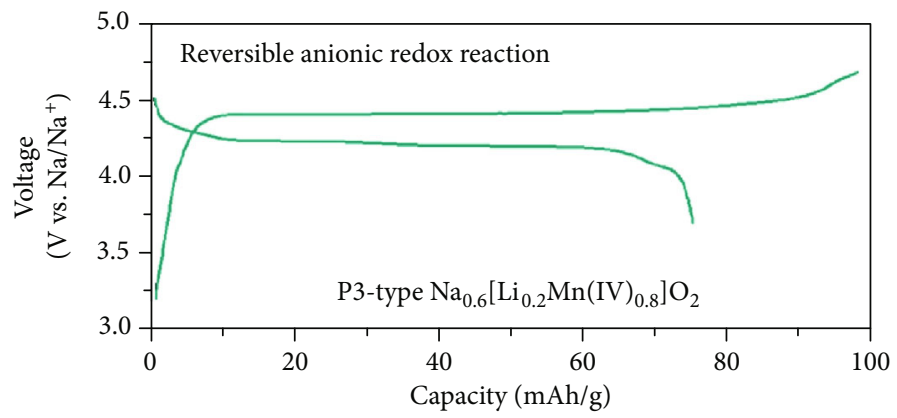

(a)

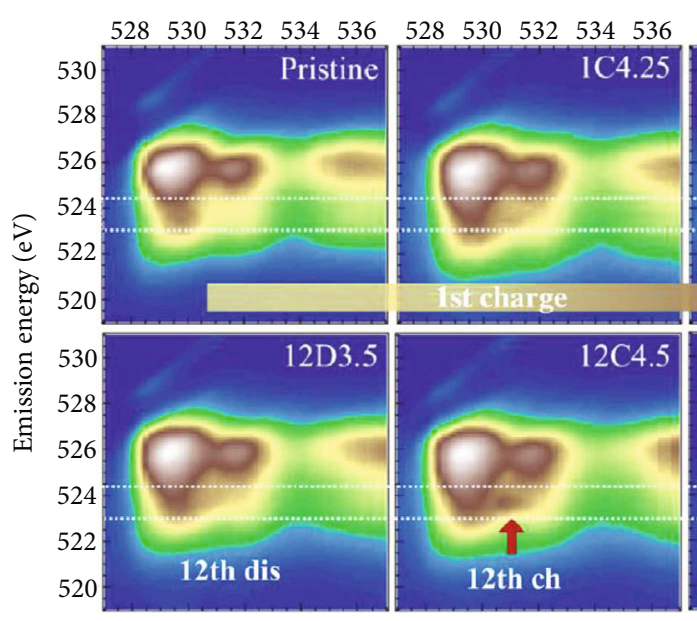

Excitation energy $(\mathrm{eV})$

$\begin{array}{lllllllllllllll}528 & 530 & 532 & 534 & 536 & 528 & 530 & 532 & 534 & 536 & 528 & 530 & 532 & 534 & 536\end{array}$

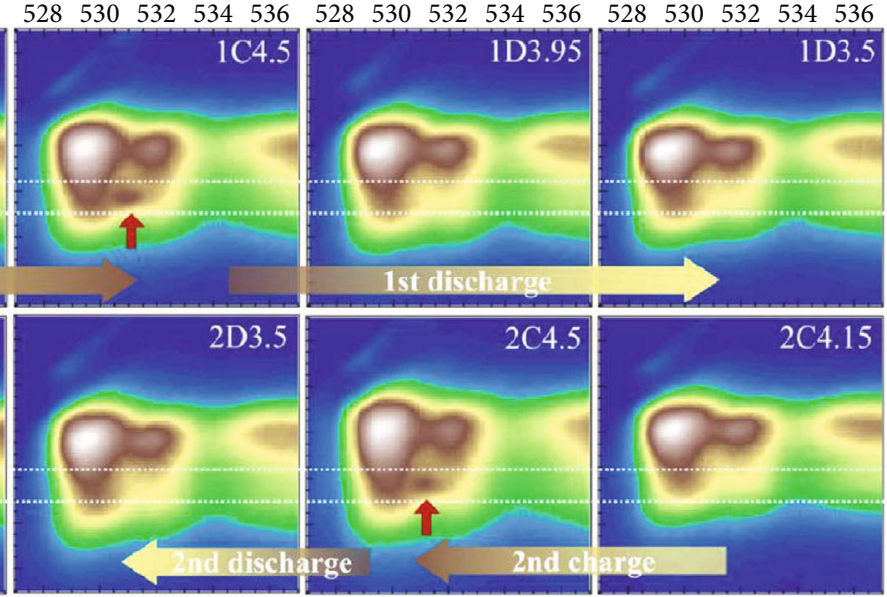

(b)

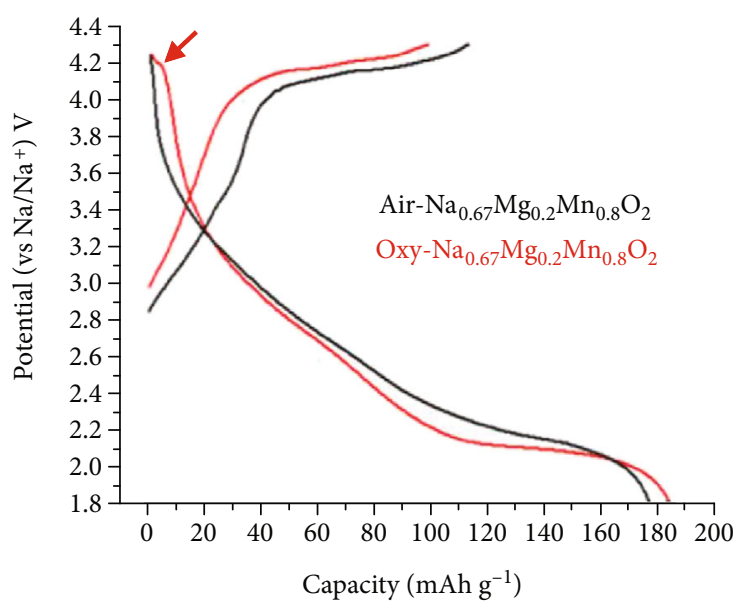

(c)

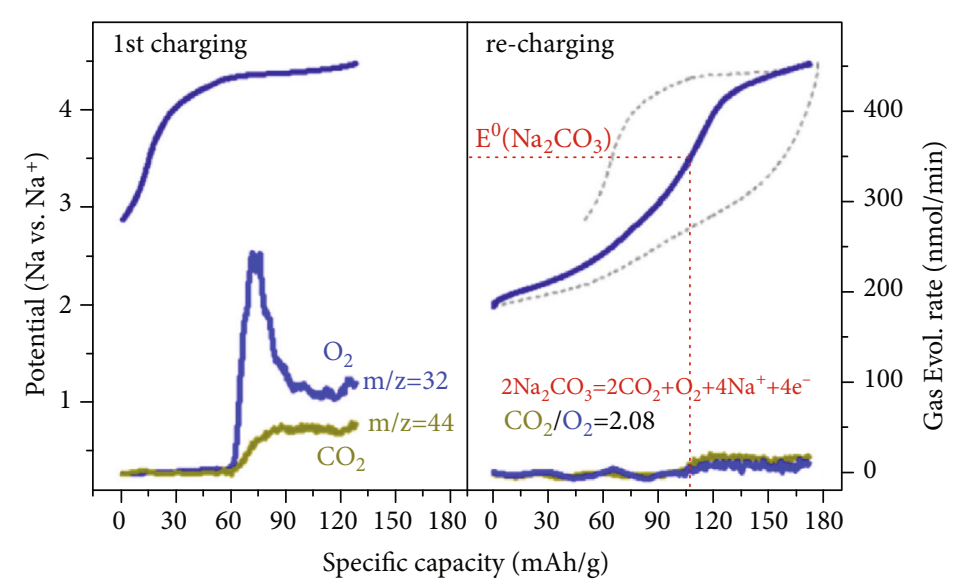

(d)

FIGURE 5: (a) The first charge and discharge curves of P3-type $\mathrm{Na}_{0.6}\left[\mathrm{Li}_{0.2} \mathrm{Mn}_{0.8}\right] \mathrm{O}_{2}$ tested in a voltage range of 3-4.5 V at $10 \mathrm{~mA} \mathrm{~g}^{-1}$ (reproduced with permission from Ref. [89], Copyright 2019 The Royal Society of Chemistry); (b) O-K mRIXS of P3-type $\mathrm{Na}_{2 / 3}\left[\mathrm{Mg}_{1 / 3} \mathrm{Mn}_{2 / 3}\right] \mathrm{O}_{2}$ at different electrochemical states, showing that red arrows indicate oxidized feature of oxygen (reprinted with permission from Ref. [90] Copyright 2020 Science Publisher); (c) charge and discharge curves on the first cycle for air$\mathrm{Na}_{0.67}\left[\mathrm{Mg}_{0.2} \mathrm{Mn}_{0.8}\right] \mathrm{O}_{2}$ (black) and oxygen- $\mathrm{Na}_{0.67}\left[\mathrm{Mg}_{0.2} \mathrm{Mn}_{0.8}\right] \mathrm{O}_{2}$ (red) with an arrow indicating reversible oxygen redox (reprinted with permission from Ref. [91], Copyright (2020) American Chemical Society); (d) in situ DEMS results of gas evolution rates for $\mathrm{O}_{2}$ and $\mathrm{CO}_{2}$ collected during the first and second charging process of P3-type $\mathrm{Na}_{0.5}\left[\mathrm{Mg}_{0.15} \mathrm{Al}_{0.2} \mathrm{Mn}_{0.65}\right]_{2}$ (reprinted with permission from Ref. [92], Copyright (2020) American Chemical Society).

provided when ionic bonds are present in TM layers, such as in the $\mathrm{Na}-\mathrm{O}-\mathrm{Li}$ ( $\mathrm{Mg}$ or $\mathrm{Zn}$ ) configuration. After oxidation of $\mathrm{Ni}$ close to $\mathrm{Ni}^{4+}$, the density of state energy of O $2 p$ in the $\mathrm{e}_{\mathrm{g}} *$
(Ni-O) becomes higher than that of the TMs, such that oxygen can be oxidized. In addition, the TM-O bonds are still hybridized, which induces irreversible capacity as a result of 
$\mathrm{O}_{2}$ release. The incorporation of more covalent character into the structure using $\mathrm{Fe}^{3+}$ in the TM layers suppressed such unfavorable reactions in highly desodiated states. Abate et al. [71] and Li et al. [72] demonstrated the readiness of the oxygen-redox reaction when $\mathrm{Fe}^{3+}$ or $\mathrm{Cu}^{2+}$ is placed at the $A$ sites in $\mathrm{Na}_{x}\left[A_{y} \mathrm{Mn}_{1-y}\right] \mathrm{O}_{2}$ rather than $\mathrm{Ni}^{2+}$. They reasoned that although the importance of $\mathrm{Na}-\mathrm{O}-\mathrm{Li}$ ( $\mathrm{Mg}$ or $\mathrm{Zn}$ ) for oxygen redox in the desodiated state is recognized, the chemical tunings by introducing such substituents can also play a role in leading to a density of state energy close to the Fermi energy level, enabling active oxygen to deliver additional capacity.

2.2. P3-Type Layered Compounds, $\mathrm{Na}_{x}\left[\mathrm{~A}_{y} \mathrm{Mn}_{1-y}\right] \mathrm{O}_{2}$ (A: $\mathrm{Li}$, $\mathrm{Mg}, \mathrm{Ni}$, and $\mathrm{Co}$ ). In general, $\mathrm{P} 3$ cathode materials have lower crystallinity than P2-type ones because heating P3-type compounds leads to the formation of the $\mathrm{P} 2$ phase at elevated temperature, usually over $900^{\circ} \mathrm{C}$. Rong et al. introduced flat charge and discharge voltage plateaus in P3 $\mathrm{Na}_{0.6}\left[\mathrm{Li}_{0.2} \mathrm{Mn}_{0.8}\right] \mathrm{O}_{2}$ (Figure 5(a)) $[88,89]$. Even though the capacity was limited to approximately $100 \mathrm{mAh} \mathrm{g}^{-1}$ in the operation range of $3-4.5 \mathrm{~V}$, it is worth noting that the obtained capacity was activated by the pure $\mathrm{O}^{2-/ 1-}$ redox pair. The associated two-phase reaction was responsible for the flat charge and discharge curves; however, the desodiated new phase was refined as another P3 phase with a smaller interlayer distance. Therefore, the migration of $\mathrm{Li}$ and $\mathrm{Mn}$ from TM layers to the Na sites was difficult due to the larger trigonal prismatic site than the octahedral one, as revealed using neutron diffraction. This immobile feature, in turn, resulted in suppression of $\mathrm{O}_{2}$ release from the lattice. $\mathrm{Wu}$ et al. [90] visualized the activity of oxygen for P3 $\mathrm{Na}_{0.6}\left[\mathrm{Li}_{0.2} \mathrm{Mn}_{0.8}\right] \mathrm{O}_{2}$, which was available for cycling (Figure 5(b)). They also pointed out that the observed nonlattice reaction on charge affected the irreversible capacity. Therefore, the P3 $\mathrm{Na}_{0.6}\left[\mathrm{Li}_{0.2} \mathrm{Mn}_{0.8}\right] \mathrm{O}_{2}$ was able to present the flat voltage plateau activated by the $\mathrm{O}^{2-/ n-}$ redox pair, which is similar to the behavior of the superstructured P2 $\mathrm{Na}_{0.6}\left[\mathrm{Li}_{0.2} \mathrm{Mn}_{0.8}\right] \mathrm{O}_{2}$ [27]. They proposed two possible factors for the capacity fade, namely, that structural disorder occurred during cycling and growth of the cathode electrolytic interface (CEI) with accumulation of oxygen-related moieties by the irreversibility on charge.

As the efficacy of $\mathrm{Mg}$ was confirmed in $\mathrm{P} 2 \mathrm{Na}_{x}\left[\mathrm{Mg}_{y} \mathrm{Mn}_{1-}\right.$ $\left.{ }_{y}\right] \mathrm{O}_{2}$ (Figure 3(a)), Kim et al. [91] investigated the availability of oxygen redox in $\mathrm{P} 3 \mathrm{Na}_{0.67}\left[\mathrm{Mg}_{0.2} \mathrm{Mn}_{0.8}\right] \mathrm{O}_{2}$. Compared to the charge capacity obtained in $\mathrm{P} 2 \mathrm{Na}_{2 / 3}\left[\mathrm{Mg}_{0.28} \mathrm{Mn}_{0.72}\right] \mathrm{O}_{2}$, the observed charge curve was rather sloppy and short (Figure 5(c)). The presence of ionic $\mathrm{Mg}-\mathrm{O}$ was responsible for the oxygen redox process. Jia et al. [92] incorporated $\mathrm{Al}$ into the $\mathrm{Mg}$ site in TM layers, $\mathrm{P} 3 \mathrm{Na}_{0.5}\left[\mathrm{Mg}_{0.15} \mathrm{Al}_{0.2} \mathrm{Mn}_{0.65}\right] \mathrm{O}_{2}$. Their operando XRD results demonstrated the suppression of the phase transition toward the $\mathrm{O} 3$ phase, although the original crystallinity was greatly reduced at the end of charge. In addition, the phase was recovered to the $\mathrm{P} 3$ phase with broadening during discharge. Surprisingly, $\mathrm{O}_{2}$ evolution was perceived on the voltage plateau over $4.1 \mathrm{~V}$ during the first charge (Figure 5(d)) [91], which contrasts with the result shown for P2 $\mathrm{Na}_{2 / 3}\left[\mathrm{Mg}_{0.28} \mathrm{Mn}_{0.72}\right] \mathrm{O}_{2}$, where no evolution of
$\mathrm{O}_{2}$ was observed up to $5 \mathrm{~V}$ (Figure 3(c)). This irreversible process can cause unexpected growth of the CEI layer on cathodes, as mentioned above for $\mathrm{P} 3 \mathrm{Na}_{0.6}\left[\mathrm{Li}_{0.2} \mathrm{Mn}_{0.8}\right] \mathrm{O}_{2}$. A similar tendency was also observed in $\mathrm{Li}\left[\mathrm{Ni}_{0.8} \mathrm{Al}_{0.2}\right] \mathrm{O}_{2}$ [93], in which oxygen evolution progressed more when $\mathrm{Al}^{3+}$ was present in the compound [92]. Similar to P2 compounds [68], reductive coupling was observed in P3 $\mathrm{Na}_{0.67}\left[\mathrm{Ni}_{0.2} \mathrm{Mn}_{0.8}\right] \mathrm{O}_{2}$ [94], and small hysteresis was observed as a result of the electroconductive $\mathrm{Co}^{3+}$ in $\mathrm{P} 3$ $\mathrm{Na}_{0.67}\left[\mathrm{Co}_{0.2} \mathrm{Mn}_{0.8}\right] \mathrm{O}_{2}$ [95]. Investigation of the oxygen-redox reaction of $\mathrm{P} 3$ has not progressed as much as that for $\mathrm{P} 2$ compounds. The voltage plateaus attributed to the oxygen-redox reaction were generally more sloppy and shorter than those observed in the P2 structure. In addition, the cyclability was inferior to that in $\mathrm{P} 2$ compounds. These findings may be related to the low crystallinity of the $\mathrm{P} 3$ structure compared with that of the $\mathrm{P} 2$ compound. In addition, the irreversible $\mathrm{O}_{2}$ evolution, which may induce the formation of a byproduct like $\mathrm{Na}_{2} \mathrm{CO}_{3}$, would result in the growth of CEI layers on the surface of cathodes. The suggested concomitant deterioration of electrodes can be circumvented by surface engineering of the active materials to make the oxygen-redox reaction more sustainable throughout cycling.

2.3. $P \overline{1}$-Type Layered Compounds $\left(\mathrm{Na}_{2} \mathrm{Mn}_{3} \mathrm{O}_{7}\right)$. An important alternative to improve upon the reversibility of oxygen-redox reactions is the use of vacancy-containing materials, as shown for the P2- $\square_{\mathrm{Mg}}$ material in Section 2.1.2. Herein, another P-type sodium-deficient cathode $\mathrm{Na}_{2} \mathrm{Mn}_{3} \mathrm{O}_{7}\left(\mathrm{Na}_{4 / 7}\left[\square_{1 / 7} \mathrm{Mn}_{6 / 7}\right] \mathrm{O}_{2}\right)$ with $\square_{\mathrm{Mn}}$ vacancies is presented [73-81]. The layered structure of $\mathrm{Na}_{2} \mathrm{Mn}_{3} \mathrm{O}_{7}$ with every seven $\mathrm{Mn}$ site vacancies $(\sqrt{7} \times \sqrt{7}$ superstucture) is displayed in Figure 6(a) [74]. $\mathrm{Na}_{2} \mathrm{Mn}_{3} \mathrm{O}_{7}$, with a valence of $\mathrm{Mn}^{4+}$, crystallizes in the triclinic $\mathrm{P} \frac{1}{1}$ structure, with half of the sodium ions occupying the distorted prism sites $(\mathrm{P})$ and the other half occupying distorted octahedral sites $(\mathrm{O}) . \mathrm{Na}_{2} \mathrm{Mn}_{3} \mathrm{O}_{7}$ possesses a notable performance with the smallest voltage hysteresis $(\sim 50 \mathrm{mV})$ among the known P2/P3/O3-type cathode materials with oxygen redox (Figure 6(b)) [74]. Furthermore, multiple reports have shown that the delivered capacity is $\sim 210-220 \mathrm{mAh} \mathrm{g}^{-1}$ in the voltage range of $1.5-4.5 \mathrm{~V}$, which is one of the highest attainable capacities for sodium cathodes with simultaneous cationic and anionic redox processes [75-77]. Despite the promising low-voltage hysteresis and high capacity, $\mathrm{Na}_{2} \mathrm{Mn}_{3} \mathrm{O}_{7}$ still suffers from degradation during cycling. Furthermore, the mechanism of the anion redox reaction with such a small hysteresis is still under debate $[78,79]$.

$\mathrm{Na}_{2} \mathrm{Mn}_{3} \mathrm{O}_{7}$ was initially studied by Adamczyk and Pralog in the low-voltage range, and it showed a specific capacity of $160 \mathrm{mAhg}^{-1}$ at $\sim 2 \mathrm{~V}$, based only on the $\mathrm{Mn}^{3+} / \mathrm{Mn}^{4+}$ redox reaction [73]. Later, several groups showed that the desodiation of $\mathrm{Na}_{2} \mathrm{Mn}_{3} \mathrm{O}_{7}$ at high voltage was governed only by the oxygen-redox reaction [75-77]. Inherent manganese vacancies in the TM layer lead to nonbonding $2 p$ orbitals of oxygen $\square_{\mathrm{Mn}}$, giving extra oxygen-redox capacity of $\sim 70-80 \mathrm{mAh} \mathrm{g}^{-1}$ at high voltage without making the $\mathrm{Mn}-\mathrm{O}$ bond labile (Figures 6(c) and 6(d)) [74]. In situ synchrotron XRD revealed negligible structural changes in the high-voltage 


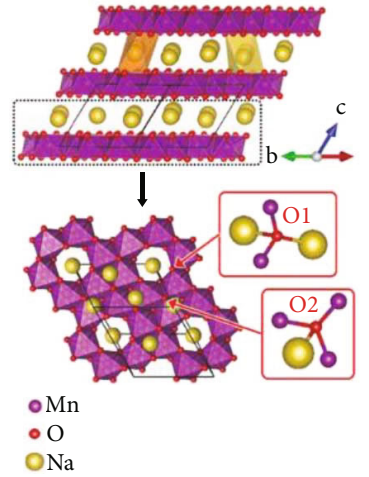

(a)

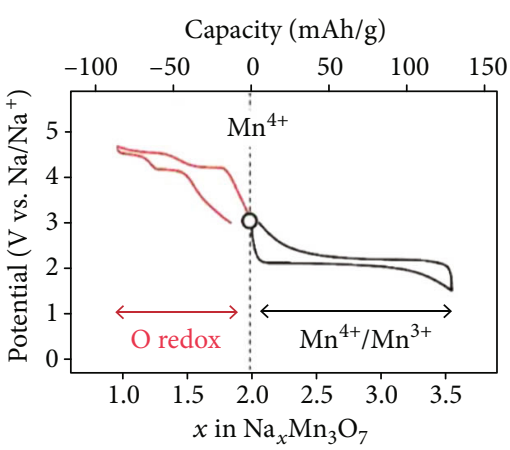

(b)
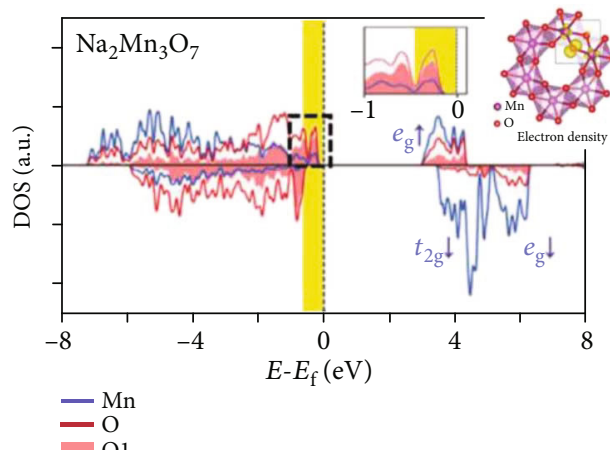

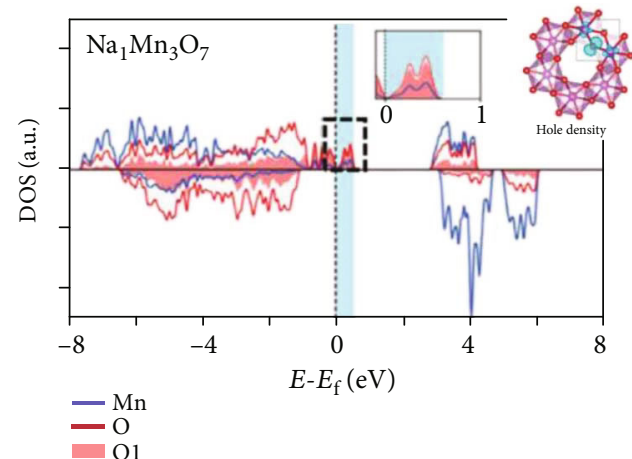

(d) (c)

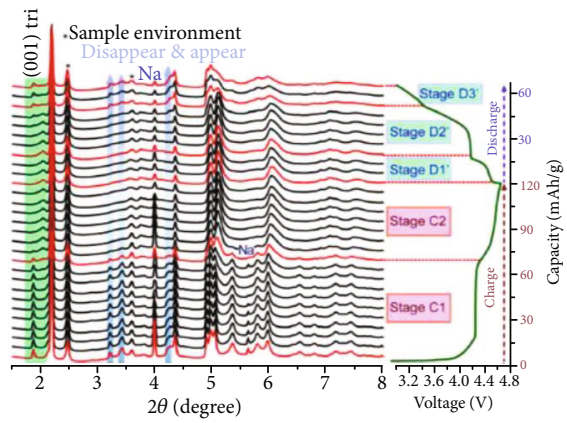

(e)

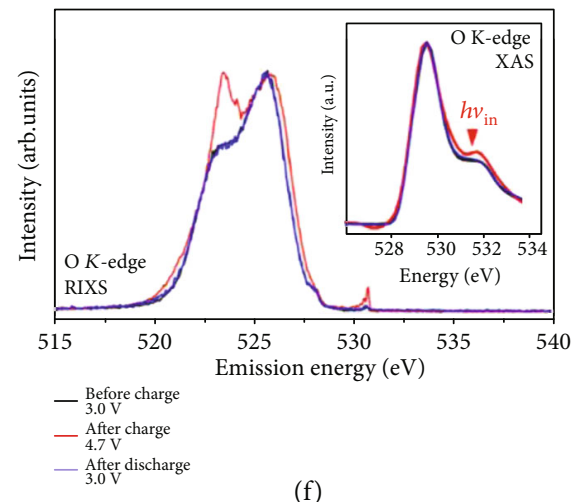

(f)

Figure 6: (a) Crystal structure of $\mathrm{Na}_{2} \mathrm{Mn}_{3} \mathrm{O}_{7}$. O coordinated by two $\mathrm{Mn}$ is labeled as $\mathrm{O} 1$, whereas $\mathrm{O}$ coordinated by three $\mathrm{Mn}$ is labeled as $\mathrm{O} 2$. $\mathrm{Mn}$ vacancies exist in the Mn layers. (b) Potential profile (second cycle) of $\mathrm{Na}_{2} \mathrm{Mn}_{3} \mathrm{O}_{7}$ upon (de)sodiation between 1.5 and $4.7 \mathrm{~V}$ versus $\mathrm{Na} / \mathrm{Na}^{+}$. (c) Calculated DOS and spatial electron density at $-0.4<E-E_{f}<0 \mathrm{eV}$ of $\mathrm{Na}_{2} \mathrm{Mn}_{3} \mathrm{O}_{7}$. (d) Calculated DOS and spatial hole density at $0<E-E f<0.55 \mathrm{eV}$ of $\mathrm{NaMn}_{3} \mathrm{O}_{7}$ (reprinted with permission from Ref. [74]. Copyright (2018) WILEY-VCH Verlag GmbH \& Co. KGaA, Weinheim). (e) In situ synchrotron XRD and lattice parameter evolution of $\mathrm{Na}_{2} \mathrm{Mn}_{3} \mathrm{O}_{7}$ during the initial charge/discharge cycle (reprinted with permission from Ref. [80]. Copyright (2019) American Chemical Society). (f) O K-edge RIXS and O K-edge XAS of $\mathrm{Na}_{2} \mathrm{Mn}_{3} \mathrm{O}_{7}$ for pristine, charged to $4.7 \mathrm{~V}$ and discharged to $3 \mathrm{~V}$ (reprinted with permission from Ref. [78]. Copyright (2021) Springer Nature).

range, which differs from the behavior of common $\mathrm{P} 2-\mathrm{O} 2$ or P2-OP4 phase transitions in P2-type materials [75]. The high structural stability of the material at high voltage (100\% after 45 cycles) was explained by the presence of intrinsic vacancies, which lead to a $\mathrm{MnO}_{6}$ octahedron with six different $\mathrm{Mn}-\mathrm{O}$ bond lengths that is more robust to desodiation. Thus, the $\left[\square_{1 / 7} \mathrm{Mn}_{6 / 7}\right] \mathrm{O}_{2}$ slab can self-regulate its deformation and improve the structural stability of the material. However, at low voltage, which is attributed to the manganese $\mathrm{Mn}^{3+} /$ $\mathrm{Mn}^{4+}$ redox reaction, a distorted lattice appeared, leading to the formation of a new phase [77]. This distorted structure was induced by the strong Jahn-Teller effect, associated with the presence of $\mathrm{Mn}^{3+}$ upon additional sodium insertion in the low-voltage region.

In light of the common high-voltage hysteresis of oxygenredox reactions, the origin of the impressive low-voltage hysteresis in $\mathrm{Na}_{2} \mathrm{Mn}_{3} \mathrm{O}_{7}$ was studied by Song et al. using ex situ/in situ paramagnetic resonance and XRD [80]. The authors claimed that the well-maintained oxygen stacking sequence together with the absence of irreversible gliding of the oxygen layers and cation migrations resulted in the highly reversible oxygen redox with a negligible voltage hysteresis between charge and discharge. The authors showed that Na-ion extraction from the octahedral site is an essentially zero-strain process, proceeding through a single-phase reaction. The extraction of sodium ions from the prismatic site occurred through a two-phase reaction $(P \overline{1}-R 3)$ with the shrinkage/expansion process of the vacant $\mathrm{MnO}_{6}$ octahedron and a larger volume change during charge/discharge (Figure 6(e)). However, the overall stacking sequence of oxygen ions was barely changed during both steps of $\mathrm{Na}$ extraction/insertion, which differs from the behavior in $\mathrm{P} 2 / \mathrm{P} 3$ cathodes, where extraction/insertion of $\mathrm{Na}$ lead to the formation of O-P phases with simultaneous decrease of the interlayer distance.

In a recent work, Tsuchimoto et al. confirmed a unique behavior of $\mathrm{O}$ in $\mathrm{Na}_{2} \mathrm{Mn}_{3} \mathrm{O}_{7}$ using DFT calculations and magnetic and spectroscopic measurements (Figure 6(f)) [78]. The existence of thermodynamically favorable $\mathrm{O}^{-\bullet}$ over the peroxide-like $\mathrm{O}_{2}{ }^{2-}$ dimers was predicted by computations and showed that hole stabilization occurred through a $(\sigma+\pi)$ multiorbital Mn-O bond. Similar predictions were reported in the work of Kitchaev et al., where a $\pi$-bonded Mn-d and O-p orbital network formed a collective delocalized redox center [81]. Therefore, the authors concluded that such a $\pi$-network rather than any local bonding environment was responsible for the two-step voltage profile with a low- 
voltage hysteresis and structural evolution observed in $\mathrm{Na}_{2} \mathrm{Mn}_{3} \mathrm{O}_{7}$.

\section{Stoichiometric Sodium Transition-Metal Layer Structures $\mathrm{Na}_{\boldsymbol{x}} \mathrm{TMO}_{2}(x=\sim 1)$}

Sodium stoichiometric layered compounds, $\mathrm{Na}_{x} \mathrm{TMO}_{2}$ $(x=\sim 1)$ known as $\mathrm{O} 3$ type, typically deliver lower discharge capacities than P2/P3-type sodium cathodes. The diffusion of sodium ions in O3-type compounds occurs from one octahedral site to another through face-shared interstitial tetrahedral sites and is characterized by relatively slow diffusion compared with that in P2/P3 structures. However, sufficient $\mathrm{Na}$ content reserved in the alkali layer guarantees a high first charge capacity and high coulombic efficiency, which is an advantage for commercial applications. In this part of the article, we will discuss the O3-type cathodes with anionic redox, in which sodium ions are located only in the alkali layer.

3.1. Mn-Based Compounds. A notable example of a O3-type cathode material with anion redox chemistry is $\mathrm{Na}\left[\mathrm{Li}_{1 / 3} \mathrm{Mn}_{2 / 3}\right] \mathrm{O}_{2}$ [85], the analog of $\mathrm{Li}\left[\mathrm{Li}_{1 / 3} \mathrm{Mn}_{2 / 3}\right] \mathrm{O}_{2}$ $\left(\mathrm{Li}_{2} \mathrm{MnO}_{3}\right)$. DFT calculations have predicted the possibility of a thermodynamically stable O3-type $\mathrm{Na}\left[\mathrm{Li}_{1 / 3} \mathrm{Mn}_{2 / 3}\right] \mathrm{O}_{2}$ structure [84]; however, for a long time, a variety of experimental conditions did not result in the formation of the pure O3-type structure. A P2-type component, in addition to other phases, was always obtained. Only recently, Wang et al. synthesized O3-type $\mathrm{Na}\left[\mathrm{Li}_{1 / 3} \mathrm{Mn}_{2 / 3}\right] \mathrm{O}_{2}(C \overline{2} m)$ by carefully adjusting the synthetic conditions and stoichiometry [85]. In $\mathrm{Na}\left[\mathrm{Li}_{1 / 3} \mathrm{Mn}_{2 / 3}\right] \mathrm{O}_{2}, \mathrm{Na}$ and $\left[\mathrm{Li}_{1 / 3} \mathrm{Mn}_{2 / 3}\right] \mathrm{O}_{2}$ stack alternatively, and $\mathrm{Li}^{+}$and $\mathrm{Mn}^{4+}$ form a honeycomb ordering within the $\left[\mathrm{Li}_{1 / 3} \mathrm{Mn}_{2 / 3}\right] \mathrm{O}_{2}$ slabs. Oxygen is coordinated by two $\mathrm{Mn}$, one $\mathrm{Li}$, and three $\mathrm{Na}$ to form an $\mathrm{OMn}_{2} \mathrm{LiNa}_{3}$ octahedron. Theoretical work by Kim et al. [84] highlighted the possibilities of oxygen redox by oxidizing $\mathrm{Na}-\mathrm{O}(2 \mathrm{p})-\mathrm{Li}$ to compensate for the electronic charge during sodium extraction in $\mathrm{Na}\left[\mathrm{Li}_{1 / 3} \mathrm{Mn}_{2 / 3}\right] \mathrm{O}_{2}$. The calculated pDOS and net charges of $\mathrm{Mn}$ and $\mathrm{O}$ confirmed that $\mathrm{Mn}$ remains as $4+$ and that the oxidation state of $\mathrm{O}$ linearly increases during $\mathrm{Na}$ removal (Figures 7(a) and 7(b)). Furthermore, their theoretical calculations were confirmed by the experimental work of Wang et al. [85]. Interestingly, the as-synthesized $\mathrm{Na}\left[\mathrm{Li}_{1 / 3} \mathrm{Mn}_{2 / 3}\right] \mathrm{O}_{2}$ material was not sensitive to moisture, and even after soaking in distilled water, it maintained its structure and crystallinity [85]. The delivered first charge capacity was $\sim 250 \mathrm{mAh} \mathrm{g}^{-1}\left(0.9 \mathrm{Na}^{+}\right.$extraction), attributed to the oxygen $\mathrm{O}^{2-} / \mathrm{O}^{1-}$ redox reaction accompanied by partial Li migration from the TM layer to the tetrahedral $\mathrm{Na}$ sites and $\mathrm{O}_{2}$ release. The resulting discharge capacity was $\sim 190 \mathrm{mAh} \mathrm{g}^{-1}$ and was maintained during 40 cycles. In situ $X R D$ revealed O3(I)-O3(II)-O3(III) structural transformations with a rapid decrease of the $c$ lattice parameter during the O3(II)-O3(III) phase transition at the first charge. Because of the $\mathrm{O}_{2}$ release and irreversible Li migration, the pristine state of the structure could not be fully recovered after discharge. In addition, partial $\mathrm{Li}^{+}$migration to the interlayer space (alkali-) sites resulted in the formation of vacan- cies in the $T M$ layer, which caused the in-plane rearrangement of $\mathrm{Mn}$ and loss of the honeycomb ordering in the TM layer. In addition to the in situ XRD analysis, Wang et al. performed Mn K-edge XAS and mRIXS analysis, which experimentally proved that both oxygen $\mathrm{O}^{2-} / \mathrm{O}^{1-}$ and $\mathrm{Mn}^{3+} / \mathrm{Mn}^{4+}$ redox were responsible for the delivered capacity.

3.2. Ru-Based Compounds. The stoichiometric sodium $\mathrm{Ru}-$ based compounds O3-type $\mathrm{Na}\left[\mathrm{Mg}_{2 / 3} \mathrm{Ru}_{1 / 3}\right] \mathrm{O}_{2}$ and $\mathrm{Na}[\mathrm{M}$ $\left.\mathrm{g}_{1 / 2} \mathrm{Ru}_{1 / 2}\right] \mathrm{O}_{2}$ ( $\left.\mathrm{R} \overline{3} \mathrm{~m}\right)$ with oxygen-redox participation were studied in the work of Jia et al. [96]. Both materials were crystallized in the $\mathrm{R} \overline{3} \mathrm{~m}$ space group; however, the oxidation state of $\mathrm{Ru}$ was different, namely, $\mathrm{Ru}^{4+}$ in $\mathrm{Na}\left[\mathrm{Mg}_{1 / 2} \mathrm{Ru}_{1 / 2}\right] \mathrm{O}_{2}$ and $\mathrm{Ru}^{5+}$ in $\mathrm{Na}\left[\mathrm{Mg}_{2 / 3} \mathrm{Ru}_{1 / 2}\right] \mathrm{O}_{2}$, respectively. On the basis of in situ XRD, Raman, and DEMS analyses, it was shown that during the first charge, $\mathrm{Na}\left[\mathrm{Mg}_{2 / 3} \mathrm{Ru}_{1 / 3}^{5+}\right] \mathrm{O}_{2}$ underwent a simple O3-O'3 transition; however, due to the $\mathrm{O}_{2}$ release at the end of charge, a specific distorted structure was formed. A more complicated sequence of O3-O'3-P3 phase transitions was observed for $\mathrm{Na}\left[\mathrm{Mg}_{1 / 2} \mathrm{Ru}_{1 / 2}^{4+}\right] \mathrm{O}_{2}$, accompanied by sluggish kinetics without $\mathrm{O}_{2}$ loss. The authors claimed that irreversible lattice oxygen loss in $\mathrm{Na}\left[\mathrm{Mg}_{2 / 3} \mathrm{Ru}_{1 / 3}^{5+}\right] \mathrm{O}_{2}$ and the formation of a distorted structure sacrificed for a more stable structure with solely $\mathrm{Ru}^{4+} / \mathrm{Ru}^{5+}$ cationic redox for the subsequent cycling. Instead of using redox-inactive $\mathrm{Mg}^{2+}$, Voronina et al. proposed to use redox-active $\mathrm{Ni}^{2+}$ to provide additional capacity and achieved reversible capacity of $154 \mathrm{mAh} \mathrm{g}^{-1}$ for $\mathrm{Na}\left[\mathrm{Ni}_{2 / 3} \mathrm{Ru}_{1 / 3}^{5+}\right] \mathrm{O}_{2}$ material [86]. DTF calculations, operando XRD, and XANES revealed reversible cationic $\mathrm{Ni}^{2+} / \mathrm{Ni}^{3+}$ and anionic $\mathrm{O}^{2-} / \mathrm{O}^{1-}$ redox reactions with no loss of $\mathrm{O}_{2}$ in the crystal structure of $\mathrm{Na}\left[\mathrm{Ni}_{2 / 3} \mathrm{Ru}_{1 / 3}^{5+}\right] \mathrm{O}_{2}$.

3.3. Ir-Based Compounds. In analogy to O3$\mathrm{Na}\left[\mathrm{Li}_{1 / 3} \mathrm{Mn}_{2 / 3}\right] \mathrm{O}_{2}$, the material $\mathrm{Na}\left[\mathrm{Li}_{1 / 3} \mathrm{Ir}_{2 / 3}\right] \mathrm{O}_{2}(C \overline{2} c)$ was proposed and investigated by Perez et al. [87]. The Li atoms preferred to stay in the center of the Ir honeycombs in the TM layer, whereas $\mathrm{Na}$ atoms occupied all the octahedral sites in the interlayer space. Cycling the material in a $\mathrm{Na}$ cell resulted in the extraction of $1.5 \mathrm{Na}^{+} / \mathrm{Li}^{+}$through a complicated multiphase process and subsequent segregation of $\mathrm{Li}$ rich $\mathrm{Li}_{x} \mathrm{IrO}_{2}$ and Na-rich $\mathrm{Na}_{x} \mathrm{IrO}_{2}$ phases. Because of the absence of calculations and further experimental investigation of the reaction mechanism together with the $\mathrm{Na} / \mathrm{Li}$ exchange during cycling, the authors were not able to arrive at a clear conclusion on the perspectives of this material. Therefore, substituting $\mathrm{Li}^{+}$with less mobile and smaller $\mathrm{Mg}^{2+}$ or $\mathrm{Zn}^{2+}$ could be a promising future direction in Irbased stoichiometric compounds with oxygen redox.

3.4. Cr-Based Compounds with Sulfur Redox. Although cathode materials with oxygen-redox reaction have received more attention to date, some studies have also considered cathode materials with sulfur redox. For example, sulfur redox has been recently investigated in stoichiometric $\mathrm{Na}$ sulfides, such as $\mathrm{O} 3-\mathrm{NaCrS}_{2}$ and $\mathrm{O} 3-\mathrm{NaCr}_{2 / 3} \mathrm{Ti}_{1 / 3} \mathrm{~S}_{2}$ [97, 98]. Originally, the sulfur-redox chemistry in chalcogenides can be traced back to the work of Whittingham on $\mathrm{TiS}_{2}$ in 1976 in Li cells [99], and the reaction mechanism is explained 


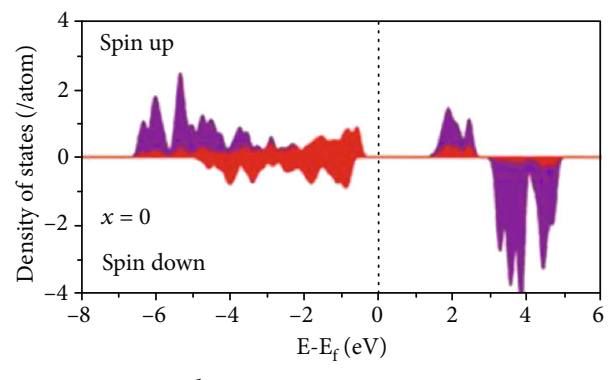

$\operatorname{Mn} 3 d$

(a-1)

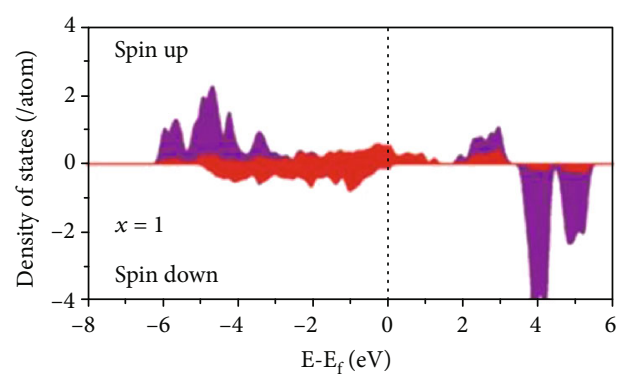

Mn $3 d$

(a-2)

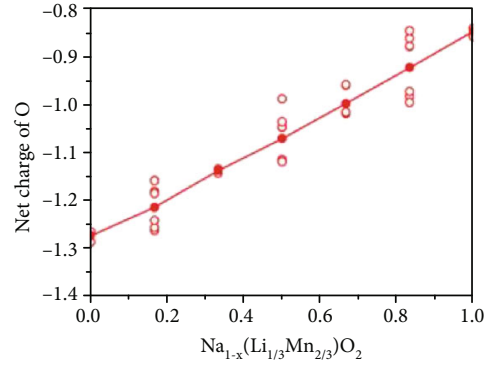

- Net charges of $\mathrm{O}$

- Average net charges of $\mathrm{O}$

(b-1)

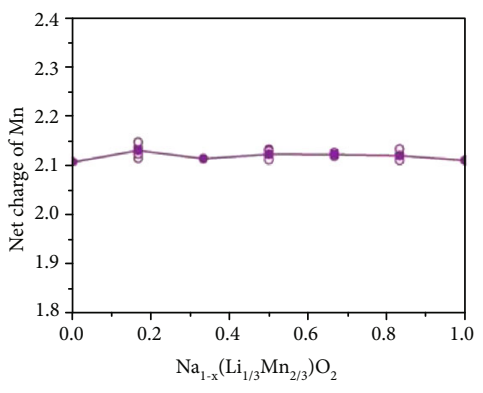

O Net charges of Mn

- Average net charges of Mn

(b-2)

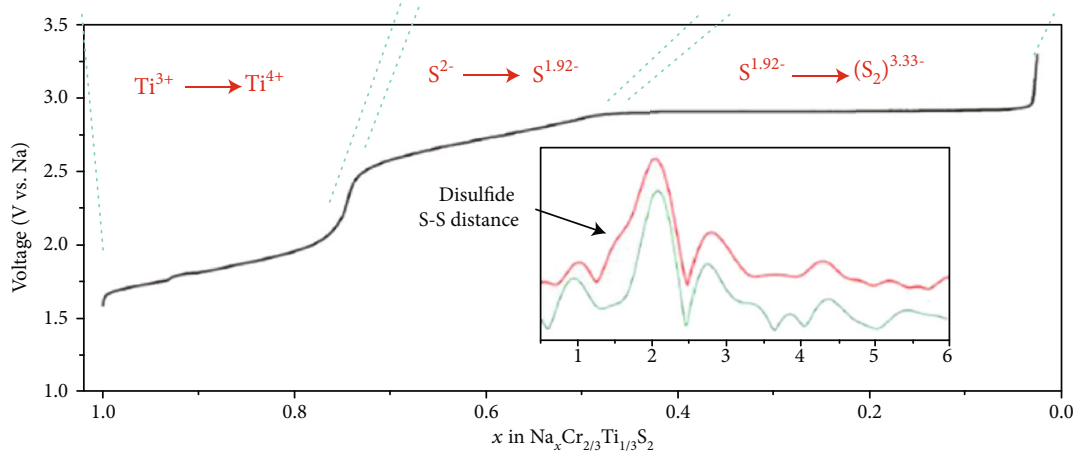

— Pristine

— Full charged

(c)

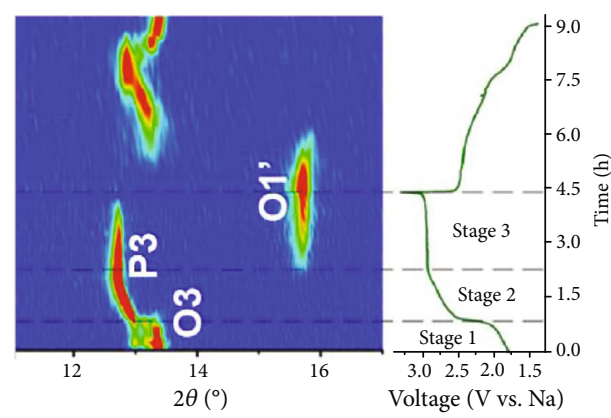

(d)

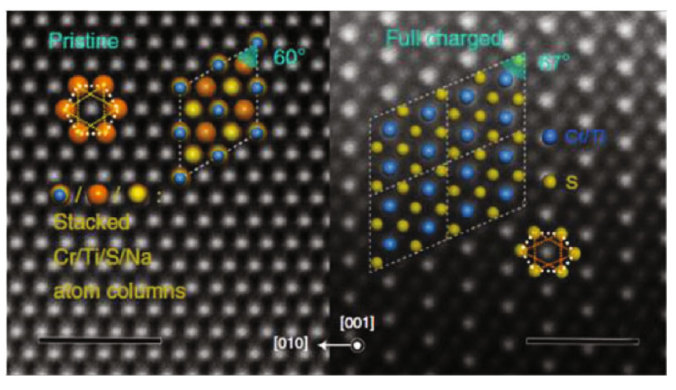

(e)

Figure 7: (a-1) PDOS of Mn 3d orbital electrons (purple) and $\mathrm{O} 2 \mathrm{p}$ orbital electrons (red) from $x=0$ and $(\mathrm{a}-2) x=0.1$ in $\mathrm{Na} \mathrm{a}_{1-x}$ $\left(\mathrm{Li}_{1 / 3} \mathrm{Mn}_{2 / 3}\right) \mathrm{O}_{2}$. (b-1) Calculated net charges, based on Bader charge analysis for $\mathrm{O}$ and (b-2) for $\mathrm{Mn}$ as a function of Na content (reprinted with permission from Ref. [84]. Copyright (2020) WILEY-VCH Verlag GmbH \& Co. KGaA, Weinheim). (c) Voltage profile of first charge and corresponding electrochemical reaction. (d) Operando XRD of $\mathrm{NaCr}_{2 / 3} \mathrm{Ti}_{1 / 3} \mathrm{~S}_{2}$ during the first cycle at a rate of C/5. (e) STEM image of pristine and fully charged $\mathrm{NaCr}_{2 / 3} \mathrm{Ti}_{1 / 3} \mathrm{~S}_{2}$ electrodes (reprinted with permission from Ref. [80]. Copyright (2019) Nature Publishing Group). 
in detail by Rouxel in 1996 [100]. However, only recently, attempts have been made to utilize sulfur redox in Cr-based $\mathrm{Na}$ cathodes. In the work of Shadike et al., $\mathrm{NaCrS}_{2}$ underwent $\mathrm{Na}^{+}$extraction/insertion through a solid-solution reaction with the occurrence of $\mathrm{Cr} / \mathrm{Na}$ vacancy antisite (cation migration to the $\mathrm{Na}$ layer) with high-voltage hysteresis and poor reversibility [97]. A similar phenomenon of $\mathrm{Cr}$ migration to the $\mathrm{Li}$ sites was observed earlier in $\mathrm{LiCrO}_{2}$ oxide [101]. In $\mathrm{LiCrO}_{2}$, the oxidation of $\mathrm{Cr}$ from $3+$ to $4+$ on charge resulted in disproportionation and further migration of $\mathrm{Cr}$ to tetrahedral sites, forming a rocksalt structure. The authors claimed that in $\mathrm{NaCrS}_{2}$, the migration of $\mathrm{Cr}$ occurred without its oxidation, which triggered sulfur redox. The prerequisite for sulfur redox was an unhybridized S $3 p$ orbital that was provided by $\mathrm{Cr}$ migration to the $\mathrm{Na}$ layer and changed the configuration symmetry around $S$, resulting in the formation of the $\mathrm{Na}-\mathrm{S}-\square$ configuration.

In an effort to increase the delivered capacity and decrease the voltage hysteresis, which is associated with $T M$ disorder, the authors spearheaded attempts to stabilize $\mathrm{Cr}$ in the TM layer through doping of $\mathrm{Ti}^{3+}$ into the $\mathrm{NaCrS}_{2}$ structure [98]. The capacity of $\mathrm{NaCr}_{2 / 3} \mathrm{Ti}_{1 / 3} \mathrm{~S}_{2}$ was boosted to $186 \mathrm{mAh} \mathrm{g}^{-1}$ due to the synergetic effect of the anion $\mathrm{S}^{2}$ ${ }^{-} / \mathrm{S}^{1-}$ and cation $\mathrm{Ti}^{3+} / \mathrm{Ti}^{4+}$ redox reactions without $\mathrm{Cr}$ participation (Figure $7(\mathrm{c})$ ). The in situ XRD results showed that the material underwent a sequence of O3-P3-O1' phase transitions with the shortening of the $a / b$ lattice parameter and a large reduction of the $c$ lattice parameter in the region of the P3-O1' transition (Figure 7(d)). Doping of $\mathrm{Ti}^{3+}$ was unsuccessful in preventing $\mathrm{Cr}$ migration from the TM layer to $\mathrm{Na}$ vacancies in the $\mathrm{P} 3-\mathrm{O} 1$ ' region. However, the authors claimed that migration of $\mathrm{Cr}$ was a highly reversible process and that the main reason for the capacity loss was not migration of $\mathrm{Cr}$ but the loss of sulfur (Figure 7(e)). Using experimental and theoretical methods, including K-edge XAS, STEM, XPS, and DFT $+\mathrm{U}$, it was possible to trace the different stages of the compensation mechanism such as the formation of electron holes, anionic dimers, and disulfide-like species as well as the precipitation of sulfur. According to those results, various anionic redox chemistries were proposed as follows:

$$
\begin{gathered}
\mathrm{S}^{2-}-(2-n) \mathrm{e}^{-} \leftrightarrow \mathrm{S}^{n-}(\text { electron holes })(1.92<n<2) \\
2 \mathrm{~S}^{1.92-}-(3.84-n) \mathrm{e}^{-} \leftrightarrow\left(\mathrm{S}_{2}\right) n-(\text { dimers })(3.33<n<3.84)
\end{gathered}
$$

$$
2 \mathrm{~S}^{2-}-2 \mathrm{e}^{-} \leftrightarrow\left(\mathrm{S}_{2}\right)^{2-} \text { (disulfides) }
$$

$$
\left(\mathrm{S}_{2}\right)^{2-}-2 \mathrm{e}^{-} \longrightarrow\left(\mathrm{S}_{2}\right) \text { (sulfur) }
$$

Electron holes of $\mathrm{S}$ were formed at the top of $3 p$ band, which was accompanied with $\mathrm{P} 3$ phase evolution process (Equation (1)). Further, the formation of $\left(S_{2}\right)^{n-}$ dimers was occurred, and it was triggered by noncoordinated S $3 p$ states (Equation (2)). The weakening of $\mathrm{Cr}-\mathrm{S}$ electrostatic repulsion caused $\mathrm{Cr}$ migration from TM layer to Na layer, resulting in P3-O1' phase transformation. The direct observation of $\mathrm{Cr}$ migration was obtained using STEM. The anion defects and formation of $\left(\mathrm{S}_{2}\right)^{2-}$ (Equation (3)), followed with irreversible oxidation or disproportionation of disulfides to sulfur (Equation (4)), occurred on the surface of the particles with the subsequent sulfur dissolution in electrolyte. The dissolution of sulfur was proved by measuring XPS spectra of the glass fiber separator before and after 10 and 50 cycles.

In conclusion, despite the $T M$ cation migration and lower operation voltage in sulfides than in oxides, the high reversibility of the sulfur redox pushes further research works on chalcogenide materials for SIBs. For mitigation of cation migration, different doping types can be implemented to improve the cycling stability; furthermore, Cr-based chalcogenides can be expanded to different TM chalcogenides.

3.5. Other Compounds. Besides the above-discussed compounds with anion-redox participation, some more Nastoichiometric cathodes, such as $\alpha-\mathrm{NaFeO}_{2}$ and $\mathrm{NaVO}_{3}$, have been reported. $\alpha-\mathrm{NaFeO}_{2}(R \overline{3} \mathrm{~m})$ is a promising low-cost layered material with a typical $\mathrm{O} 3$ structure. However, it suffers from irreversible capacity with poor cycling performance. The underlying reaction mechanism and such irreversible behavior are still under debate. $\alpha-\mathrm{NaFeO}_{2}$ material was first reported in 1985 by Kikkawa et al., [102] followed by a research of Yabuuchi et al. [103], Zhao et al. [104], and Lee et al. [105] groups. $\alpha-\mathrm{NaFeO}_{2}$ delivered $80-100 \mathrm{mAh} \mathrm{g}^{-1}$ of reversible capacity with a flat voltage plateau at $3.3 \mathrm{~V}$ vs. $\mathrm{Na}$ (Figure 8(a)). The reversible capacity in the range of $\mathrm{Na}_{1 \text { - }}$ ${ }_{x} \mathrm{FeO}_{2}, x<0.5$, was ascribed to $\mathrm{Fe}^{3+} / \mathrm{Fe}^{4+}$ redox reaction and was confirmed by ${ }^{57} \mathrm{Fe}$ Mössbauer spectrometry [104]. The electrode performance beyond $x>0.5$ was deteriorated and exhibited irreversible structural behavior, which the authors suggest is due to Fe ion migration to neighboring tetrahedral sodium sites and subsequently blocking the diffusion sodium pathways [103]. Lee et al. first showed the nonequilibrium phase transformation during charge/discharge process from hexagonal $(R \overline{3} \mathrm{~m})$ to monoclinic $(\mathrm{C} 2 / \mathrm{m})$ phase, accompanied with the evidence of the chemical instability of $\mathrm{Fe}^{4+}$ species and electrolyte decomposition in the battery cell environment [105].

Recently, Li et al. [106] observed not only the irreversible Fe migration from TM layer to Na layer at the atomic scale by aberration-corrected scanning transmission electron microscopic (STEM), but also oxidation of oxygen during desodiation of $\alpha-\mathrm{NaFeO}_{2}$ using XAS spectra. Moreover, DFT calculations showed that near Fermi level, the Fe $3 d$ and $\mathrm{O}$ $2 p$ states are highly overlapping, which means that both $\mathrm{Fe}$ and $\mathrm{O}$ contribute to charge compensation. In contrast to the Li et al.'s work, Susanto et al. [107] revealed that only oxygen redox responsible for charge compensation from the beginning of charging of $\alpha-\mathrm{NaFeO}_{2}$. When more than 0.5 $\mathrm{Na}$ was extracted, $\mathrm{O}_{2}$ gas was released together with $\mathrm{Fe}$ migration and the formation of $\mathrm{Fe}_{3} \mathrm{O}_{4}$ (cubic spinel $\mathrm{Fd} \overline{3} \mathrm{~m}$ ) locally on the surface of the particles (Figure 8(b)). Therefore, reversible charge compensation mechanism through solely oxygen redox was limited up to 0.5 of $\mathrm{Na}$ extraction. To address this critical issue, partial substitution of $\mathrm{Fe}$ with other TM has been reported previously. However, the participation of oxygen redox has not been shown in sufficient detail, which emphasizes the need for further systematic studies of such materials. 


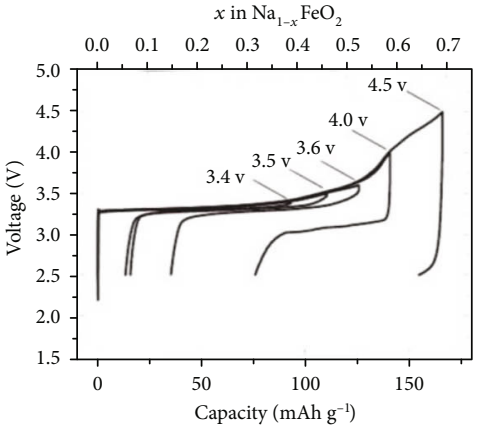

(a)

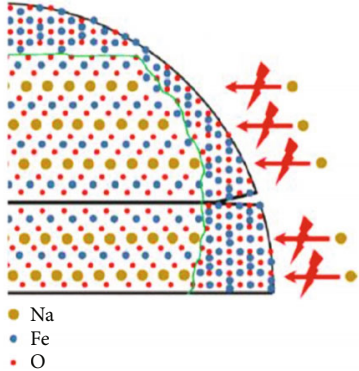

(b)

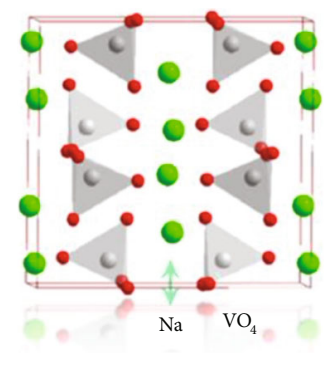

(c)

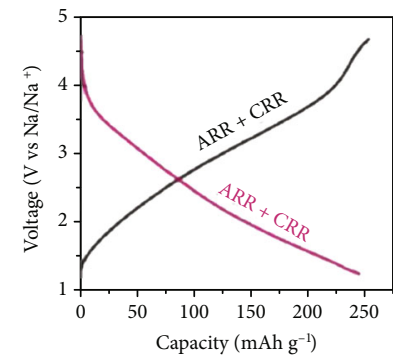

(d)

Figure 8: (a) Charge-discharge profiles of $\alpha-\mathrm{NaFeO}_{2}$ (reprinted with permission from Ref. [104]. Copyright (2012) The Electrochemical Society of Japan). (b) Schematic illustration of irreversible $\mathrm{Na}^{+}$intercalation. Formation of $\mathrm{Fe}_{3} \mathrm{O}_{4}$ on the surface of $\alpha-\mathrm{NaFeO}$. Reprinted with permission from Ref. [107]. Copyright (2019) American Chemical Society. (c) Crystal structure of $\mathrm{NaVO}_{3}$. (d) Charge-discharge curve of $\mathrm{NaVO}_{3}$ (reprinted with permission from Ref. [109]. Copyright (2020) American Chemical Society).

In addition, oxygen-redox participation has also been investigated in stoichiometric layered $\mathrm{NaVO}_{3}$ material [108, 109].The material crystallizes into a layered structure with monoclinic $\mathrm{C} 2 / \mathrm{c}$ space group, where layers of $\mathrm{NaO}_{6}$ octahedra and $\mathrm{VO}_{4}$ tetrahedra alternate (Figure $8(\mathrm{c})$ ). On the basis of in situ synchrotron XRD results, the structure of the material showed insignificant changes during $\mathrm{Na}^{+}$(de-)intercalation with $a$ and $b$ lattice parameter variation only by 0.13 and $0.19 \%$, respectively [109]. A more detailed study on electrochemical process revealed that $\mathrm{NaVO}_{3}$ undergoes an oxygen-redox reaction during initial charge and cationic $\mathrm{V}^{4+} / \mathrm{V}^{5+}$ and anionic $\mathrm{O}^{2-} / \mathrm{O}^{1-}$ redox during subsequent discharge (Figure $8(\mathrm{~d})$ ). Oxygen charge compensation mechanism was proved by DFT calculation showing the domination of $\mathrm{O} 2 p$ states for partially and fully desodiated structure. The delivered reversible capacity was reached $245 \mathrm{mAh} \mathrm{g}^{-1}$, leading to one of the most highest energy densities $\left(566 \mathrm{Wh} \mathrm{kg}^{-1}\right.$ ) for SIB materials with anion-redox participation.

\section{Sodium-Rich Transition Metal Layer Structures $\mathrm{Na}_{\boldsymbol{x}} \mathrm{TMO}_{2}(x>1)$}

Na-rich materials, $\mathrm{Na}_{1}\left[\mathrm{Na}_{x} T M_{1-x}\right] \mathrm{O}_{2}$, which are analogs of Li-rich materials, are promising materials for highperformance SIBs owing to their high sodium content, offering an opportunity to increase the energy density of SIBs. In sodium-rich materials, sodium ions are located in both alkali and TM layers (octahedral sites), in contrast to full sodiumstoichiometry and deficient materials, in which sodium ions are located only in the alkali layer. The extra $\mathrm{Na}$ content may provide extra capacity, delivered by cumulative cationic and anionic redox, potentially exceeding $1 \mathrm{Na}^{+}$per formula unit.

4.1. Mn-Based Compounds. In contrast to their lithium-ion analogs, where lithium-rich $\mathrm{Li}_{2} T M \mathrm{O}_{3}\left(\mathrm{Na}\left[\mathrm{Na}_{1 / 3} T M_{2 / 3}\right] \mathrm{O}_{2}\right)$ type oxides ( $T M: \mathrm{Mn}, \mathrm{Mo}, \mathrm{Ru}$, and $\mathrm{Ir}$ ) have been synthesized and studied for $3 \mathrm{~d} T M(\mathrm{Mn})$ and $4 \mathrm{~d} / 5 \mathrm{~d} T M(\mathrm{Mo}, \mathrm{Ru}$, and $\mathrm{Ir})$, sodium-rich oxides $\mathrm{Na}_{2} \mathrm{TMO}_{3}$ have been successfully obtained only for $4 \mathrm{~d}(\mathrm{Ru})$ and $5 \mathrm{~d} T M(\mathrm{Ir})$. The reason for that is likely the larger ionic radius mismatch between $\mathrm{Na}^{+}$ $(1.02 \AA)$ and $\mathrm{Mn}^{4+}(0.53 \AA)$. Therefore, to date, there is no a clear evidence of the crystal structure or electrochemical performance of $\mathrm{Na}_{2} \mathrm{MnO}_{3}$. The material has been discussed only in computer simulations. According to the theoretical work of Gao et al., it is possible to extract $1.75 \mathrm{Na}^{+}$per formula unit through partial $\mathrm{O}^{2-} / \mathrm{O}^{1-}$ redox reaction leaving much of the local structure intact [110].

4.2. Ru-Based Compounds. The oxygen-redox chemistry was demonstrated in sodium-rich Ru-based cathodes with good structural stability [30-42]. The first research paper on such materials was published in 2013 by the group of Tamaru et al. on $\mathrm{Na}_{2} \mathrm{RuO}_{3}(R \overline{3} \mathrm{~m})$, in which Ru was stabilized as $\mathrm{Ru}^{4+}$ [30]. The material delivered a specific capacity of $140 \mathrm{mAh} \mathrm{g}^{-1}$, which exceeded $7 \%$, the theoretical capacity from only $\mathrm{Ru}^{4+} / \mathrm{Ru}^{5+}$ redox. Sloppy charge/discharge curves were observed with an average potential of $2.8 \mathrm{~V}$ vs. $\mathrm{Na} / \mathrm{Na}^{+}$. It was indicated that the reaction mechanism proceeded through a solid-solution reaction $\left(\mathrm{Na}_{2-x} \mathrm{RuO}_{3} 0<x<0.5\right)$, followed by a two-phase reaction $(0.5<x<0.6)$. Later in 2015, Rozier's group designed $\mathrm{Sn}$-doped layered $\mathrm{Na}_{2} \mathrm{Ru}_{1}$ ${ }_{-y} \mathrm{Sn}_{y} \mathrm{O}_{3}$ materials [31]. The voltage profiles of the $\mathrm{Sn}$ doped materials were similar to those of Li-rich materials with two distinct voltage plateaus on charge ( 2.8 and $3.8 \mathrm{~V}$ ) and an S-curved shape on discharge. Using XPS analysis, the authors proved that the lower voltage plateau was associated with cationic $\mathrm{Ru}^{4+} / \mathrm{Ru}^{5+}$ redox and that the higher one was associated with anionic $\mathrm{O}^{2-} / \mathrm{O}_{2}{ }^{n-}$ redox. Similar to De Boisse et al.'s work, a solid-solution-two-phase-solid solution mechanism was observed during $\mathrm{Na}$ deintercalation.

In a more recent study, De Boisse et al. synthesized honeycomb ordered $\mathrm{O}-\mathrm{Na}_{2} \mathrm{RuO}_{3}(\mathrm{C} 2 / \mathrm{m})$ and the disordered ana$\log \mathrm{D}-\mathrm{Na}_{2} \mathrm{RuO}_{3}(R \overline{3} \mathrm{~m})$ [32] and investigated the importance of structural order/disorder of alkali and TM ions in the TM layer (Figure 9(a)). The authors claimed that the order in the $T M$ layer is a prerequisite for the activation of oxygen redox, induced by frontier orbital $\mathrm{O}(2 \mathrm{p})-\mathrm{Ru}\left(\mathrm{t}_{\mathrm{g}}\right)$ reorganization with the short $\mathrm{O}-\mathrm{O}$ distances in distorted $\mathrm{RuO}_{6}$. Because of the inplane honeycomb ordering, the $\mathrm{O}-\mathrm{Na}_{2} \mathrm{RuO}_{3}$ electrode demonstrated enhanced capacity of $180 \mathrm{mAh} \mathrm{g}^{-1}$ compared with 


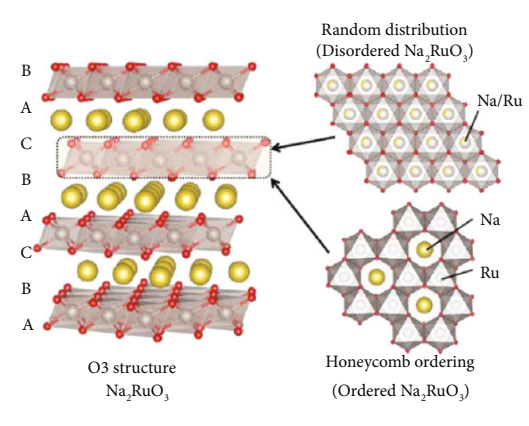

(a)

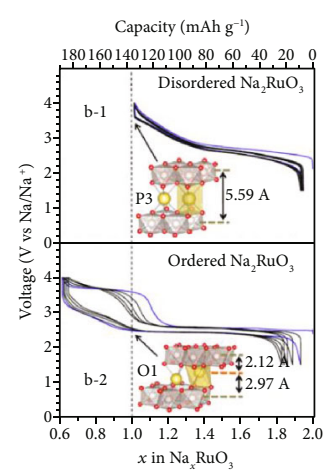

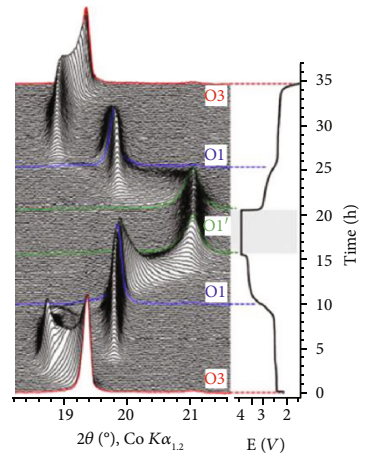

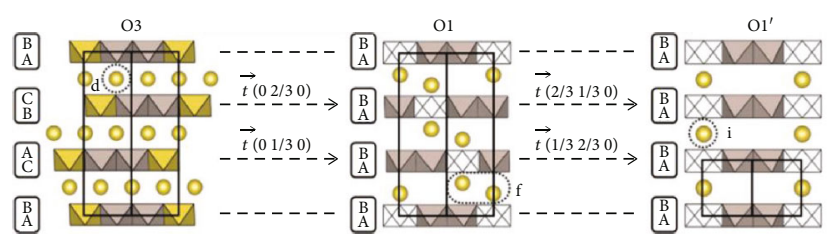

(d)

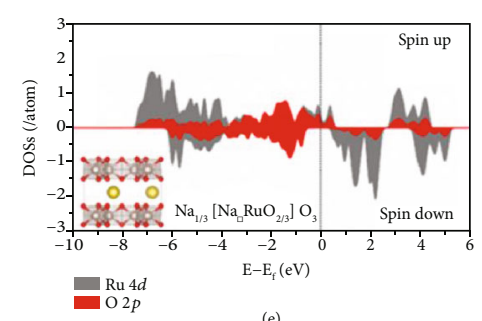

(e)

Figure 9: (a) Structure of ordered and disordered $\mathrm{Na}_{2} \mathrm{RuO}_{3}$. (b) Electrochemical properties of disordered and ordered $\mathrm{Na}_{2} \mathrm{RuO}_{3}(\mathrm{reprinted}$ with permission from Ref. [32]. Copyright (2016) Nature Publishing Group). (c) In situ XRD pattern during the first cycle of $\mathrm{Na}_{2} \mathrm{RuO}_{3}$ with the corresponding cycling curve. (d) Crystal structures of $\mathrm{O} 3-\mathrm{Na}_{2} \mathrm{RuO}_{3}, \mathrm{O} 1-\mathrm{Na}_{1} \mathrm{RuO}$, and $\mathrm{O} 1$ ' $-\mathrm{Na}_{1 / 2} \mathrm{RuO}_{3}$ phases (reprinted with permission from Ref. [33]. Copyright (2019) Nature Publishing Group). (e) Combined partial density of state (PDOS) profiles of Ru 4d and O 2p electrons in $\mathrm{Na}_{1 / 3}\left[\mathrm{Na}_{\square} \mathrm{Ru}_{2 / 3}\right] \mathrm{O}_{2}$ (reprinted with permission from Ref. [34]. Copyright (2020) American Chemical Society).

that of $135 \mathrm{mAhg}^{-1}$ for $\mathrm{D}-\mathrm{Na}_{2} \mathrm{RuO}_{3}$ (Figure 9(b)). The authors showed that $30 \%$ extra capacity was achieved by the spontaneously ordered intermediate ilmenite $\mathrm{O} 1$ $\mathrm{Na}_{1} \mathrm{RuO}_{3}(R \overline{3})$ phase, which accommodates the cooperative distortion of the $\mathrm{RuO}_{6}$ octahedra. In contrast, in the case of disordered material, the intermediate $\mathrm{P} 3-\mathrm{Na}_{1} \mathrm{RuO}_{3}$ phase exhibited strain frustration, which did not allow activation of the oxygen-redox reaction. Further study of ordered O$\mathrm{Na}_{2} \mathrm{RuO}_{3}$ showed O3-O1-O1' structural phase transformations during charge with an intermediate $\mathrm{O} 1-\mathrm{Na}_{1} \mathrm{RuO}_{3}$ phase and $\mathrm{Ol}^{\prime}-\mathrm{Na}_{1 / 2} \mathrm{RuO}_{3}(P \overline{3} 1 \mathrm{~m})$ phase stabilized in the fully charged state (Figures 9(c) and 9(d)) [33]. The in situ XRD and DFT calculation results showed that the existence of ordered $\mathrm{Na}$ vacancies played an essential role in increasing the $\mathrm{O} 2 \mathrm{p}$ electronic population near the Fermi level, which not only stabilized the phase transformations during cycling but also facilitated reversible oxygen-redox reactions (Figure 9(e)) [34].

Moreover, in a later work of Liu et al., the $\mathrm{Mn}^{4+}$-substitution strategy was adopted in $\mathrm{Na}_{2} \mathrm{Ru}_{1-x} \mathrm{Mn}_{x} \mathrm{O}_{3}(x=0-0.3)$ material [38]. $\mathrm{Mn}^{4+}$ doping resulted in an increase of the voltage of the material due to the increase in the $\mathrm{M}-\mathrm{O}$ band ionicity and charge on $\mathrm{O}$. In addition, $\mathrm{Mn}^{4+}$ doping suppressed the O3-P3 phase transition and prevented the formation of the spinel phase in the highly desodiated state and enhanced the robustness against water attack. A surprising super long cycling stability with a capacity retention of $70 \%$ was achieved at $5 \mathrm{C}$ after 1000 cycles.

$\mathrm{Na}_{3} \mathrm{RuO}_{4}\left(\mathrm{Na}\left[\mathrm{Na}_{1 / 2} \mathrm{Ru}_{1 / 2}\right] \mathrm{O}_{2}\right)(\mathrm{C} / \mathrm{m})$ is a further expansion of the $\mathrm{Na}_{2} \mathrm{RuO}_{3}$ cathode material toward higher sodium content $(\mathrm{O} / \mathrm{TM}$ ratio) Ru-based materials with oxygen-redox activity [40-42]. The crystal structure of $\mathrm{Na}_{3} \mathrm{RuO}_{4}$ is described as a layered structure with a $\mathrm{Ru}^{5+}$ framework forming isolated tetramers of the edge-sharing $\mathrm{RuO}_{6}$ octahedra in the $\mathrm{Na}_{1 / 2} \mathrm{Ru}_{1 / 2} \mathrm{O}_{2}$ layer (Figure 10(a)) [41]. The reaction mechanism in $\mathrm{Na}_{3} \mathrm{RuO}_{4}$ is currently under debate by several groups [40-42]. The first work of Qiao et al. on the chemical extraction of $\mathrm{Na}$ from $\mathrm{Na}_{3} \mathrm{RuO}_{4}$ indicated that capacity is delivered by merely $\mathrm{O}$ redox reaction through the formation of peroxo-based O-O (de)bonding, which was confirmed by in situ Raman analysis (Figure 10(b)) [40]. On the basis of the XPS and XANES analyses, the authors claimed that $\mathrm{Na}$ extraction/insertion proceeded along the inert redox character of $\mathrm{Ru}^{5+}$ in the octahedral position. However, Otoyama et al. later revisited this compound and showed that the charge compensation mechanism includes the participation of both $\mathrm{Ru}$ and $\mathrm{O}$ redox reactions [41]. First, the oxidation of $\mathrm{Ru}^{5+}$ to $\mathrm{Ru}^{6+}$ occurs, leading to the formation of $\mathrm{Na}_{2} \mathrm{RuO}_{4}\left(\mathrm{P}_{1} / \mathrm{c}\right)$, followed by oxygen reduction at the end of charge through a solid-solution process with the formation of amorphous $\mathrm{Na}_{x} \mathrm{RuO}_{4}(x=0-1)$. The presented O-redox reaction proceeded together with the dissolution of the active material, which subsequently led to the irreversible reaction and poor recovery of the $\mathrm{Na}_{3} \mathrm{RuO}_{4}$ structure with its initial crystallinity [41]. In the work of $\mathrm{Hu}$ et al. [42], similar results were shown, clarifying that both $\mathrm{Ru}^{5+} / \mathrm{Ru}^{6+}$ and $\mathrm{O}^{2-} / \mathrm{O}^{1-}$ are active, and it was shown that the oxygen-redox activity decreased with a retention of $36 \%$ after 30 cycles, which was the main reason for the large capacity fading and limited reversibility.

To conclude, $\mathrm{Na}_{3} \mathrm{RuO}_{4}$ showed electrostatically more unstable behavior upon deep desodiation than $\mathrm{Na}_{2} \mathrm{RuO}_{3}$, which could be explained by the higher $\mathrm{Na}$ vacancy content 


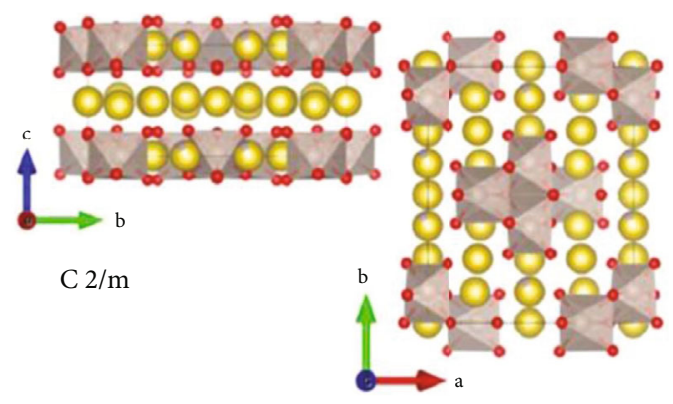

(a)

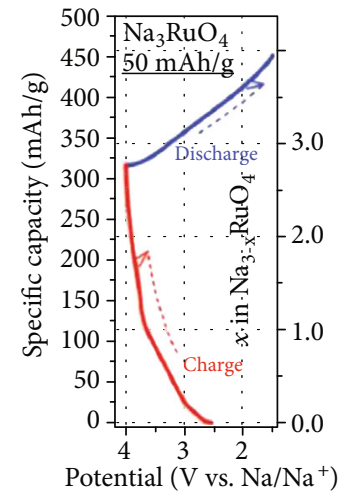

Potential (V vs. $\mathrm{Na} / \mathrm{Na}^{+}$)

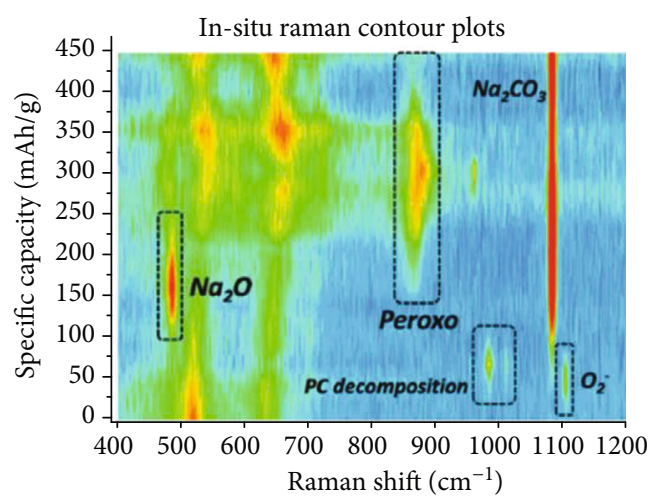

(b)

Figure 10: (a) Crystal structure of $\mathrm{Na}_{3} \mathrm{RuO}_{4}$ (reprinted with permission from Ref. [41]. Copyright (2019) WILEY-VCH Verlag GmbH \& Co. KGaA, Weinheim). (b) Voltage profile of first cycle and capacity dependent in situ Raman spectral contour plot (reprinted with permission from ref [40]. Copyright (2018) The Royal Society of Chemistry).

and only a single-TM-coordinate oxygen ions. This finding highlights the importance of balance upon increasing the number of nonbonding $\mathrm{O}$ states for the reversibility of the oxygen-redox reaction and structural stability of the material.

4.3. Ir-Based Compounds. The O3-type $\mathrm{Na}_{2} \mathrm{IrO}_{3}$ $\left(\mathrm{Na}\left[\mathrm{Na}_{1 / 3} \mathrm{Ir}_{2 / 3}\right] \mathrm{O}_{2}\right)(\mathrm{C} 2 / \mathrm{m})$ compound is another example of a Na-rich composition that displays oxygen-redox activity [43]. In contrast to $3 \mathrm{~d}(\mathrm{Mn})$ and $4 \mathrm{~d}(\mathrm{Ru}) \mathrm{TM}$ compounds, which present drastic evolution of the voltage profile through the first cycle, the $5 \mathrm{~d}$ (Ir) $\mathrm{Na}_{2} \mathrm{IrO}_{3}$ material did not show an evolution from a two-plateau to S-shape voltage profile (Figure 11(a)). The enhanced structural rigidity of the compound allowed cycling of the cell reversibly upon high sodium extraction/insertion $\left(1.5 \mathrm{Na}^{+}\right.$per formula unit, capacity $\sim 130 \mathrm{mAh} \mathrm{g}^{-1}$ ) with neither oxygen release or cationic migrations to interlayer (alkali-) sites. During extraction of sodium ions, the O3-type layered structure first converted to O1' $(P \overline{1})$ and further to O1 $(C \overline{2} m)$ through gliding of the oxygen close-packed planes (Figure 11(b)). The increased cationic repulsion with charge density loss on the $\mathrm{O}$ atom leads to a high covalent TM-O bond, which reduces the possibility of $\mathrm{O}_{2}$ release and effectively stabilizes the structure. Using DFT calculations, the authors indicated that both the Ir and O bands lay just below the Fermi level, which involve both oxygen $\mathrm{O}^{2-} / \mathrm{O}^{1-}$ and $\mathrm{Ir}^{4+} / \mathrm{Ir}^{5+}$ contributions in charge compensation (Figures 11(c) and 11(d)). Interestingly, that oxygen-redox activity was observed in the early stage of the desodiation process, which the author linked to the slightly distorted $\mathrm{IrO}_{6}$ octahedra in the pristine $\mathrm{Na}_{2} \mathrm{IrO}_{3}$ material (Figures 11(c) and 11(d)).

To overcome the drawback of the high cost of $5 \mathrm{~d}$ (Ir) TM, Zhang et al. proposed the partial substitution of Ir by Mn and obtained $\mathrm{Na}_{1.2} \mathrm{Mn}_{0.4} \mathrm{Ir}_{0.4} \mathrm{O}_{2}$ [44]. The authors reported reasonable reversible capacity of $135 \mathrm{mAh} \mathrm{g}^{-1}$ with $1.5 \mathrm{~mol} \mathrm{Na}^{+}$ extraction during the first charge. Interestingly, that charge compensation mechanism was attributed to $\mathrm{Mn}^{3+} / \mathrm{Mn}^{4+}$ cationic redox and $\mathrm{O}^{2-} / \mathrm{O}^{1-}$ oxygen redox without Ir participation. In situ Raman and XPS analyses were employed to confirm the reversibility of the $\mathrm{O}_{2}{ }^{2-}$ formation. Even though
Ir did not participate in the electrochemical reaction throughout the entire charge and discharge process, $\mathrm{Na}_{1.2} \mathrm{M}$ $\mathrm{n}_{0.4} \mathrm{Ir}_{0.4} \mathrm{O}_{2}$ demonstrated similar to $\mathrm{Na}_{2} \mathrm{IrO}_{3}$ asymmetric transformation during charge, especially in the $\mathrm{O}^{\prime} 1-\mathrm{O} 1$ phase region. The authors explained this finding with potential stacking faults, which were caused by a systematic shift of $T M$ layers.

A viable alternative for improving the performance of $\mathrm{Na}_{2} \mathrm{IrO}_{3}$ was proposed by Pearce et al. by synthesizing a fundamentally different crystal structure of $\beta-\mathrm{Na}_{1.7} \mathrm{IrO}_{3}$ [45]. $\beta$ $\mathrm{Na}_{1.7} \mathrm{IrO}_{3}$ was obtained by the electrochemical exchange of $\mathrm{Li}$ into $\mathrm{Na}$ in $\beta-\mathrm{Li}_{2} \mathrm{IrO}_{3}$ material. In the structure of $\beta$ $\mathrm{Na}_{1.7} \mathrm{IrO} \mathrm{I}_{3}$, the $\mathrm{Na}$ and Ir layers were shifted relative to each other; instead of a layered structure, the material acquires a Fddd hyperhoneycomb structure with a rigid 3D network (Figures 11(e) and 11(f)). It turned out that such a hyperhoneycomb structure was much more stable, with reversible uptake of nearly $1.3 \mathrm{Na}^{+}$and good capacity retention of $82 \%$ after 100 cycles in a full-cell configuration against hard carbon. Despite the fact that the $\beta-\mathrm{Na}_{1.7} \mathrm{IrO}_{3}$ material underwent multiple structural phase transitions with different lattice parameters and a large volume change $\sim 26 \%$ during sodiation/desodiation, it maintained the same $\mathrm{IrO} 3$ framework (Figure 11(g)). The charge-compensation mechanism revealed that both the anionic $\left(\mathrm{O}_{2}\right)^{n-}$ redox and cationic activity of $\mathrm{Ir}^{5+} / \mathrm{Ir}^{4+}$ were responsible for the delivered capacity.

In summary, 5d Ir-based compounds exhibit more reversible charge/discharge curves than $4 \mathrm{~d} T M$ and especially 3d TM compounds, suggesting higher structural integrity due to more diffused orbitals against the irreversible reactions of oxidized oxygen. However, because Ir is one of the rarest metals in the Earth's crust and because of its high cost, the use of such cathodes is of little practical importance.

\section{Biphasic Layered Structures}

To achieve better electrode performance, an attractive approach of the combination of $\mathrm{P} / \mathrm{O}$ phases in one material was recently proposed. The synergetic effect of the 


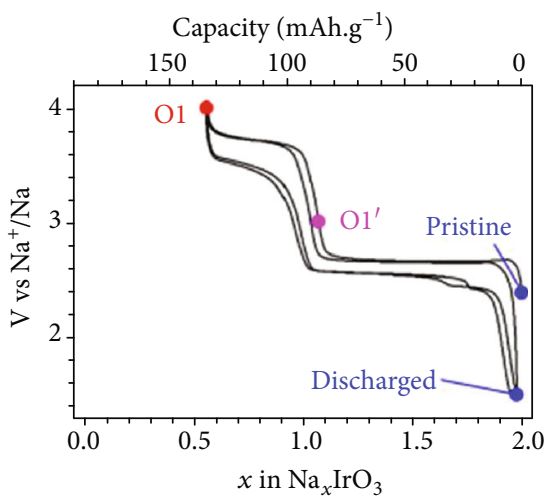

(a)

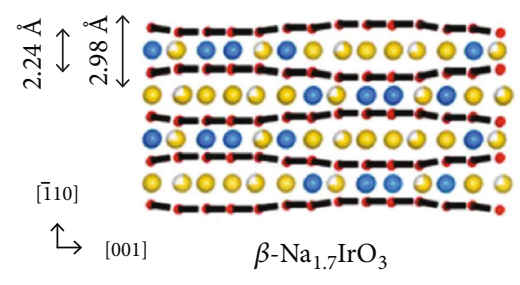

(e)

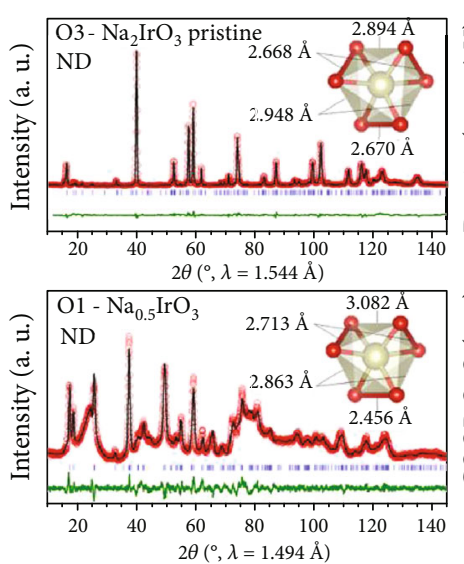

(b)

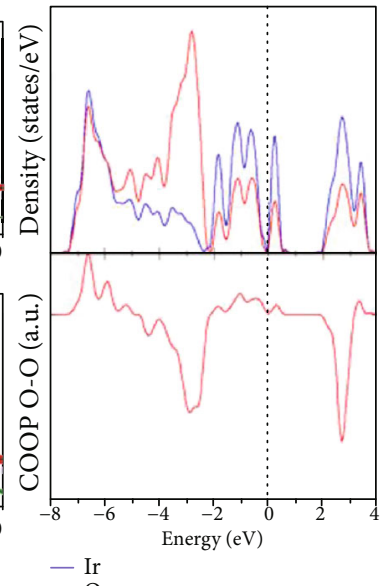

(c)

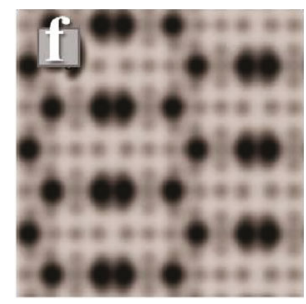

(f)

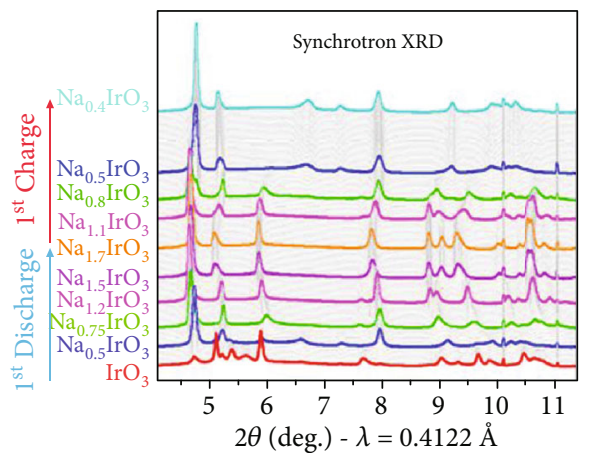

(g)
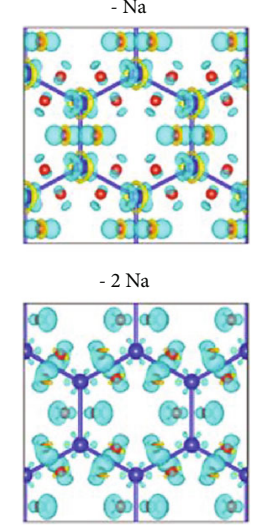

(d)

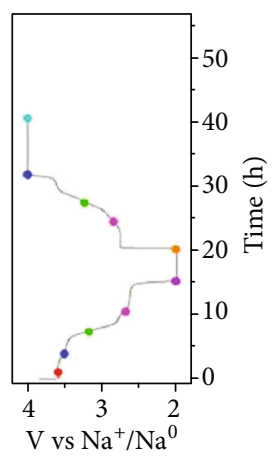

$\mathrm{V}$ vs $\mathrm{Na}^{+} / \mathrm{Na}^{0}$

FIGURE 11: (a) First and second galvanostatic cycles of $\mathrm{O} 3-\mathrm{Na}_{2} \mathrm{IrO}_{3}$ vs. Na. (b) Refinement of neutron diffraction patterns for the O3-Na $\mathrm{IrO}_{3}$ and $\mathrm{O} 1-\mathrm{Na}_{0.5} \mathrm{IrO}_{3}$ structures. (c) Projected DOS and O-O crystal orbital overlap population (COOP) of $\mathrm{Na}_{2} \mathrm{IrO}_{3}$. (d) Respected presentation of electron density differences (reprinted with permission from Ref. [43]. Copyright (2016) American Chemical Society). (e) Structure of $\beta$ $\mathrm{Na}_{1.7} \mathrm{IrO}_{3}$. (f) ABF-STEM simulation of the $\beta-\mathrm{Na}_{1.7} \mathrm{IrO}_{3}$. (g) Synchrotron operando XRD patterns of $\beta$-IrO $\mathrm{I}_{3}$ charged vs. Na ${ }^{+} / \mathrm{Na}$ and subsequent charge together with the corresponding charge profile (reprinted with permission from Ref. [45]. Copyright (2018) American Chemical Society).

combination of a two-phase composite was observed by Yang et al. in $\mathrm{P} 2 / \mathrm{O} 3 \mathrm{Na}_{0.8} \mathrm{Li}_{0.2} \mathrm{Fe}_{0.2} \mathrm{Mn}_{0.6} \mathrm{O}_{2}$, in which Fe was stabilized as $3+$ and $\mathrm{Mn}$ as $4+[111]$. The material delivered a reversible capacity of $174 \mathrm{mAh}^{-1}$, which was attributed to $\mathrm{Fe}^{3+} / \mathrm{Fe}^{4+}$ redox along with partial $\mathrm{Mn}^{3+} /{ }^{4+}$ redox and oxygen contribution. Using NMR $\mathrm{Li}^{7}$, it was shown that a portion of lithium migrated from the TM layer to the alkali layer during the first charge. However, further distribution of lithium between the Na layer and TM layer remained constant during electrochemical cycles. The biphasic O/P nature of the material was nevertheless preserved, and lithium was considered the structure stabilizer.

$\mathrm{Hu}$ et al. attempted to further improve the structural stability of this $\mathrm{P} 2 / \mathrm{O} 3 \mathrm{Na}_{0.8} \mathrm{Li}_{0.2} \mathrm{Fe}_{0.2} \mathrm{Mn}_{0.6} \mathrm{O}_{2}$ composite using $\mathrm{Ti}^{4+}$ doping into $\mathrm{Mn}^{4+}$-sites [112]. Combining solid-state NMR, EPR, XPS, and HRTEM analyses, the authors demonstrated that $\mathrm{Ti}^{4+}$ substitution could not only effectively suppress lithium migration from the TM layer to the $\mathrm{Na}$ layer but also enhanced the structural stability by alleviating the formation of irreversible surface cracks on particles during cycling.

In conclusion, successful utilization of $\mathrm{O} / \mathrm{P}$ composites as a cathode material with anion redox to increase the energy density and improve the first coulombic efficiency appears to be a promising strategy, further expanding the variety of potential anion redox materials for SIBs.

\section{Cation-Disordered Rocksalt Oxides}

Over the last five years, Li-rich cation-disordered rocksalttype structure oxides with oxygen redox compensation mechanism have emerged as potential high energy density cathodes for LIBs with high reversible capacities $\sim 300 \mathrm{mAhg}^{-1}$ and extremely high energy densities $\sim 1000 \mathrm{~W} \mathrm{~h} \mathrm{~kg}^{-1}$ [113]. Oxygen-redox activity in such systems associated with a highly ionic character of $\mathrm{d}^{0}$ charge compensator metal ions, such as $\mathrm{Ti}^{4+} / \mathrm{Zr}^{4+} / \mathrm{Nb}^{5+} / \mathrm{Mo}^{6+}$.

The concept of Li-rich rocksalt structures was recently applied to Na-rich materials [114, 115]. Sato et al. synthesized a metastable $\mathrm{Na}$-rich cation-disordered rocksalt oxides, which exhibit the oxygen-redox activity. $\mathrm{Na}_{1.3} \mathrm{Nb}_{0.3} \mathrm{Mn}_{0.4} \mathrm{O}_{2}$ [114] and $\mathrm{Na}_{1.14} \mathrm{Mn}_{0.57} \mathrm{Ti}_{0.29} \mathrm{O}_{2}$ [115] have a cubic-close packed (ccp) structure, which presented in XRD with a broad diffraction peaks, indicating the formation of small size and low crystallinity samples, obtained by mechanical milling 
process. The reversible capacity was $\sim 200 \mathrm{mAh} \mathrm{g}^{-1}$ for both materials, despite the different reaction mechanism.

For $\mathrm{Na}_{1.3} \mathrm{Nb}_{0.3} \mathrm{Mn}_{0.4} \mathrm{O}_{2}$, the detailed investigation of electrochemical process revealed that $\mathrm{Mn}^{3+} / \mathrm{Mn}^{4+}$ redox prevailed at low voltage, while $\mathrm{O}$ oxidation accompanied with $\mathrm{O}_{2}$ loss dominated at high voltage on first charge. As a result, accumulation of carbonate species and $\mathrm{O}_{2}$ loss were detected at fully charged state in $\mathrm{Na}_{1.3} \mathrm{Nb}_{0.3} \mathrm{Mn}_{0_{2} 4} \mathrm{O}_{2}$ electrode. Therefore, only reversible two-electron $\mathrm{Mn}^{2+} / \mathrm{Mn}^{4+}$ redox rather than reversible oxygen redox were observed on the subsequent cycles. By substituting $\mathrm{Nb}^{5+}$ with $\mathrm{Ti}^{4+}$, the reversibility of oxygen redox was significantly improved in $\mathrm{Na}_{1.14} \mathrm{Mn}_{0.57 \text { - }}$ $\mathrm{Ti}_{0.29} \mathrm{O}_{2}$. Reversible cationic $\mathrm{Mn}^{3+} / \mathrm{Mn}^{4+}$ without reduction to $\mathrm{Mn}^{2+}$ and anionic $\mathrm{O}^{2-} / \mathrm{O}^{n-}$ redox reactions were responsible for delivered capacity in $\mathrm{Na}_{1.14} \mathrm{Mn}_{0.57} \mathrm{Ti}_{0.29} \mathrm{O}_{2}$. Moreover, not only the reversibility of anionic redox has been highly improved compared with the former $\mathrm{Na}_{1.3} \mathrm{Nb}_{0.3} \mathrm{Mn}_{0.4} \mathrm{O}_{2}$ material, but also cycling stability of $\mathrm{Na}_{1.14} \mathrm{Mn}_{0.57} \mathrm{Ti}_{0.29} \mathrm{O}_{2}$ was greatly increased. Therefore, further research in $\mathrm{Na}-$ rich cation-disordered rocksalt cathodes from abundant elements, such as manganese and titanium, with reversible anionic redox is required for the development of high energy density rechargeable SIBs.

\section{Conclusions}

The use of cathode materials with both anion- and cationredox reactions represents a promising approach toward important gains in the energy density of SIBs. The estimation of the gravimetric energy density for P2-type materials with cationic and anionic redox is $\sim 500-600 \mathrm{Wh} \mathrm{kg}^{-1}$ and that for O3-type materials is $\sim 400 \mathrm{Wh} \mathrm{kg}^{-1}$, which is very promising (Figure 12). To date, considerable progress has been achieved for Na-rich (O3-type) and Na-deficient (P2-type) materials. Most of the emphasis on Na-rich materials has been on rare and expensive $4 \mathrm{~d} T M(\mathrm{Ru})$ and $5 \mathrm{~d} T M(\mathrm{Ir})$ elements; however, $\mathrm{Na}$-deficient materials rely on the use of low-cost 3d TM (Mn). Therefore, from a practical viewpoint, P2-type materials have considerable merits such as low cost, high performance, and relatively stable oxygen-redox reactions, making them promising for SIBs with improved energy density. However, recent work of Wang et al. [85] showed that a new Na-stoichiometric compound O3$\mathrm{Na}\left[\mathrm{Li}_{1 / 3} \mathrm{Mn}_{2 / 3}\right] \mathrm{O}_{2}$ not only offers an effective possibility of utilizing anionic redox but also does not have the drawback of low coulombic efficiency. Moreover, from this viewpoint, mixed P2/O3-type oxides represent an interesting strategy, leading to high-performance materials with enhanced air stability and relatively high sodium content.

From a practical viewpoint, the main drawbacks of materials with anion redox are their severe microstructural and electrochemical instabilities. Therefore, it is critical to understand the origin of these issues and to find ways to mitigate them. Among the microstructural issues, the most significant involve oxygen evolution, cation migration, and surface reconstruction. The principal electrochemical problems in anion redox reactions in SIBs are the sluggish reaction kinetics, high-voltage hysteresis (compared to cationic redox), and voltage fade during cycling, which in turn adversely affect the

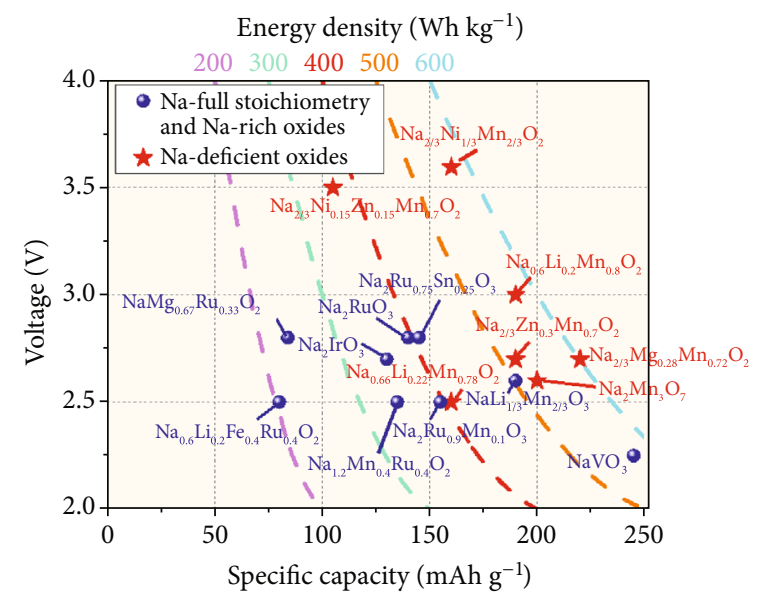

FIgURE 12: Comparison of energy densities of reported oxygen redox-based cathode materials for SIBs.

electrochemical performance. The slow reaction kinetics is mostly caused by drastic rearrangements of bonding configurations; however, high-voltage hysteresis and voltage fade have largely been attributed to the structural cation disordering in plane and out of plane in the material during cycling. Therefore, we would like to provide some important solutions for optimization of the properties of cathode materials with cationic-anionic redox for SIBS.

(1) One of the critical concerns for anion-redox cathodes is the nature of the oxidized species, which needs to be better understood and characterized, especially because it defines the chemical reactivity and solubility of the material. Therefore, the use of a combination of experimental and theoretical techniques, such as $\mathrm{O}-\mathrm{K}$ mRIXS, in situ XRD/ND, XAS, and Raman methods together with DFT calculations, is critical because these observations and predictions provide a critical benchmark for the detection and determination of the nature of the oxidized species in cathode materials

(2) The concept of an ordered compositional approach has been successfully realized in $\mathrm{P} 2-\mathrm{Na}_{0.6}\left[\mathrm{Li}_{0.2} \mathrm{Mn}_{0.8}\right] \mathrm{O}_{2}$, $\mathrm{O} 3-\mathrm{Na}_{2} \mathrm{RuO}_{3}$, and $\mathrm{Na}_{2} \mathrm{Mn}_{3} \mathrm{O}_{7}$ materials and has resulted in beneficial properties with good structural stability, high reversibility of anion redox, and lowvoltage hysteresis. However, a nonhysteresis profile has been demonstrated only for $\mathrm{Na}_{2} \mathrm{Mn}_{3} \mathrm{O}_{7}$. This unique behavior makes it a key compound for understanding the chemical, structural, and electronic properties for engineering materials with truly reversible nonhysteretic anion redox. Therefore, further theoretical predictions and additional approaches should be expanded to determine the reasons for the nonhysteretic behavior of $\mathrm{Na}_{2} \mathrm{Mn}_{3} \mathrm{O}_{7}$ and to identify more compounds with high electrochemically reversible and kinetically easy anion redox processes

(3) Another factor affecting the stability of cation-anion redox reactions is the surface chemistry of the cathode material. Complex reactions together with 
oxygen evolution occur at the electrode/electrolyte boundary at high voltage, leading to a metastable nature of highly charged layered cathode materials. Therefore, the development of surface coatings and commodification strategies, which can overcome the challenges at the electrode/electrolyte boundary and improve the long cycling stability, should be encouraged

Overall, we are optimistic about cationic-anionic redox cathode materials for SIBs, with significant progress seen in the last 5 years. We hope that this review will shed light on the possibilities to improve such cathodes and increase research interest in the development of Earth-abundant and low-cost SIBs with anion redox activity that are aligned with the requirements for post-LIBs.

\section{Conflicts of Interest}

The authors declare that there is no conflict of interest regarding the publication of this article.

\section{Acknowledgments}

This work was supported by the Basic Science Research Program through the National Research Foundation of Korea (NRF), funded by the Ministry of Education, Science, and Technology of Korea (NRF-2015M3D1A1069713, NRF2019H1D8A2106002, NRF-2020R1A2B5B01095954, and NRF-2020R1A6A1A03043435).

\section{References}

[1] N. Yabuuchi, K. Kubota, M. Dahbi, and K. Komaba, "Research development on sodium-ion batteries," Chemical Reviews, vol. 114, no. 23, pp. 11636-11682, 2014.

[2] V. Palomares, P. Serras, I. Villaluenga, K. B. Hueso, J. Carretero-Gonzalez, and T. Rojo, "Na-ion batteries, recent advances and present challenges to become low cost energy storage system," Energy \& Environmental Science, vol. 5, no. 3, pp. 5884-5901, 2012.

[3] J.-Y. Hwang, S.-T. Myung, and Y.-K. Sun, "Sodium-ion batteries: present and future," Chemical Society Review, vol. 46, no. 12 , pp. 3529-3614, 2017.

[4] C. Delmas, J.-J. Braconnier, C. Fouassier, and P. Hagenmuller, "Electrochemical intercalation of sodium in $\mathrm{Na}{ }_{\mathrm{x}} \mathrm{CoO}_{2}$ bronzes," Solid State Ionics, vol. 3-4, pp. $165-169,1981$.

[5] J. H. Jo, J. U. Choi, Y. J. Park, H. Yashiro, and S.-T. Myung, "A new pre-sodiation additive for sodium-ion batteries," Energy Storage Materials, vol. 33, pp. 281-289, 2020.

[6] C.-H. Jo, J. U. Choi, H. Yashiro, and S.-T. Myung, "Controllable charge capacity using a black additive for high-energydensity sodium-ion batteries," Journal of Materials Chemistry A, vol. 7, no. 8, pp. 3903-3909, 2019.

[7] A. R. Armstrong and P. G. Bruce, "Electrochemistry beyond $\mathrm{Mn}^{4+}$ in $\mathrm{Li}_{\mathrm{x}} \mathrm{Mn}_{1-\mathrm{y}} \mathrm{Li}_{\mathrm{y}} \mathrm{O}_{2}$," Electrochemical and Solid-State Letters, vol. 7, no. 1, pp. A1-A4, 2004.

[8] A. R. Armstrong and P. G. Bruce, "Layered $\mathrm{Li}_{\mathrm{x}} \mathrm{Mn}_{1-\mathrm{y}} \mathrm{Li}_{\mathrm{y}} \mathrm{O}_{2}$ intercalation electrodes: synthesis, structure and electro- chemistry," Journal of Materials Chemistry, vol. 15, no. 1, pp. 218-224, 2005.

[9] N. Guerrini, L. Jin, J. G. Jozano et al., "Charging mechanism of $\mathrm{Li}_{2} \mathrm{MnO}_{3}$," Chemistry of Materials, vol. 32, no. 9, pp. 3733-3740, 2020.

[10] N. Yabuuchi, K. Yoshii, S.-T. Myung, I. Nakai, and S. Komaba, "Detailed studies of a high-capacity electrode material for rechargeable batteries, $\mathrm{Li}_{2} \mathrm{MnO}_{3}-\mathrm{LiCo}_{1 / 3} \mathrm{Ni}$ ${ }_{1 / 3} \mathrm{Mn}_{1 / 3} \mathrm{O}_{2}$," Journal of the American Chemical Society, vol. 133, no. 12, pp. 4404-4419, 2011.

[11] G. Assat and J.-M. Tarascon, "Fundamental understanding and practical challenges of anionic redox activity in Li-ion batteries," Nature Energy, vol. 3, no. 5, pp. 373-386, 2018.

[12] J. Naylor, E. Makkos, J. Maibach et al., "Depth-dependent oxygen redox activity in lithium-rich layered oxide cathodes," Journal of Materials Chemistry A, vol. 7, no. 44, pp. 2535525368, 2019.

[13] Y. Yu, P. Karayaylail, S. H. Nowak et al., "Revealing electronic signatures of lattice oxygen redox in lithium ruthenates and implications for high-energy Li-ion battery material designs," Chemistry of Materials, vol. 31, no. 19, pp. 7864-7876, 2019.

[14] P. E. Pearce, A. J. Perez, G. Rousse et al., "Evidence for anionic redox activity in a tridimensional-ordered Li-rich positive electrode $\beta$ - $\mathrm{Li}_{2} \mathrm{IrO}_{3}$," Nature Materials, vol. 16, no. 5, pp. 580-586, 2017.

[15] P. Vanaphuti, J. Bai, L. Ma et al., "Unraveling Na and F coupling effects in stabilizing $\mathrm{Li}, \mathrm{Mn}$-rich layered oxide cathodes via local ordering modification," Energy Storage Materials, vol. 31, pp. 459-469, 2020.

[16] C. Gong, S. D. Pu, X. Gao et al., "Revealing the role of fluoride-rich battery electrode interphase by operando transmission electron microscopy," Advanced Energy Materials, vol. 10, no. 11, article 2003118, 2021.

[17] N. Yabuuchi, R. Hara, M. Kajiyama et al., "New O2/P2-type Li-excess layered manganese oxides as promising multifunctional electrode materials for rechargeable Li/Na batteries," Advanced Energy Materials, vol. 4, no. 13, article 1301453, 2014.

[18] M. B. Yahia, J. Vergnet, M. Saubanere, and M. L. Doublet, "Unified picture of anionic redox in Li/Na-ion batteries," Nature Materials, vol. 18, no. 5, pp. 496-502, 2019.

[19] X. Rong, E. Hu, Y. Lu et al., “Anionic redox reaction-induced high-capacity and low-strain cathode with suppressed phase transition," Joule, vol. 3, no. 2, pp. 503-517, 2019.

[20] C. Zhao, Q. Yang, F. Geng et al., "Restraining oxygen loss and boosting reversible oxygen redox in a P2-type oxide cathode by trace anion substitution," ACS Applied Materials \& Interfaces, vol. 13, no. 1, pp. 360-369, 2021.

[21] E. de la Llave, E. Talaie, E. Levi et al., "Improving energy density and structural stability of manganese oxide cathodes for Na-ion batteries by structural lithium substitution," Chemistry of Materials, vol. 28, no. 24, pp. 9064-9076, 2016.

[22] X. Chen, N. Li, E. Kedzie, B. D. McCloskey, H. Tang, and W. Tong, "High-capacity P2-type $\mathrm{Na}_{\mathrm{x}} \mathrm{Li}_{0.25} \mathrm{Mn}_{0.75} \mathrm{O}_{2}$ cathode enabled by anionic oxygen redox," Journal of the Electrochemical Society, vol. 166, no. 16, pp. A4136-A4140, 2019.

[23] Y. Zhu, W. Nie, P. Chen, Y. Zhou, and Y. Xu, "Li-doping stabilized $\mathrm{P} 2-\mathrm{Li}_{0.2} \mathrm{Na}_{1.0} \mathrm{Mn}_{0.8} \mathrm{O}_{2}$ sodium ion cathode with oxygen redox activity," International Journal of Energy Research, vol. 44, no. 4, pp. 3253-3259, 2020. 
[24] C. Li, C. Zhao, B. Hu, W. Tong, M. Shen, and B. Hu, "Unraveling the critical role of Ti substitution in $\mathrm{P} 2-\mathrm{Na}_{\mathrm{x}} \mathrm{Li}_{\mathrm{y}} \mathrm{Mn}_{1-\mathrm{y}} \mathrm{O}_{2}$ cathodes for highly reversible oxygen redox activity," Chemistry of Materials, vol. 32, no. 3, pp. 1054-1063, 2020.

[25] S. M. Kang, D. Kim, K.-S. Lee et al., "Structural and thermodynamic understandings in Mn-based sodium layered oxides during anionic redox," Advanced Science, vol. 6, no. 16, article 2001263, 2020.

[26] D. Kim, M. Cho, and K. Cho, "Rational design of $\mathrm{Na}\left(\mathrm{Li}_{1 / 3} \mathrm{Mn}_{2 / 3}\right) \mathrm{O}_{2}$ operated by anionic redox reactions from advanced sodium-ion batteries," Advanced Materials, vol. 29, no. 33, article 1701788, 2017.

[27] R. A. House, U. Maitra, M. A. Perez-Osorio et al., "Superstructure control of first-cycle voltage hysteresis in oxygen-redox cathodes," Nature, vol. 577, no. 7791, pp. 502-508, 2020.

[28] Q. Liu, Z. Hu, W. Li et al., "Sodium transition metal oxides: the preferred cathode choice for future sodium-ion batteries?," Energy \& Environmental Science, vol. 14, no. 1, pp. 158-179, 2021.

[29] X. Cao, H. Li, Y. Qiao et al., "Stabilizing reversible oxygen redox chemistry in layered oxides for sodium-ion batteries," Advanced Energy Materials, vol. 10, no. 15, article 1903785, 2020.

[30] M. Tamaru, X. Wang, M. Okubo, and A. Yamada, "Layered $\mathrm{Na}_{2} \mathrm{RuO}_{3}$ as a cathode material for Na-ion batteries," Electrochemistry Communications, vol. 33, pp. 23-26, 2013.

[31] P. Rozier, M. Sathiya, A. R. Paulraj et al., "Anionic redox chemistry in Na-rich $\mathrm{Na}_{2} \mathrm{Ru}_{1-\mathrm{y}} \mathrm{Sn}_{\mathrm{y}} \mathrm{O}_{3}$ positive electrode material for Na-ion batteries," Electrochemistry Communications, vol. 53, pp. 29-32, 2015.

[32] B. Mortemard De Boisse, G. Liu, J. Ma et al., "Intermediate honeycomb ordering to trigger oxygen redox chemistry in layered battery electrode," Nature Communications, vol. 7, pp. 1-9, 2016.

[33] B. Mortemard de Boisse, M. Reynaud, J. Ma et al., "Coulombic self-ordering upon charging a large-capacity layered cathode material for rechargeable batteries," Nature Communications, vol. 10, no. 1, article 2185, 2019.

[34] G. Choi, J. Lee, and D. Kim, "Uncovering the structural evolution in Na-excess layered cathodes for rational use of an anionic redox reaction," ACS Applied Materials and Interfaces, vol. 12, no. 26, pp. 29203-29211, 2020.

[35] M. H. N. Assadi, M. Okubo, A. Yamada, and Y. Tateyama, "Oxygen redox promoted by Na excess and covalency in hexagonal and monoclinic $\mathrm{Na}_{2-\mathrm{x}} \mathrm{RuO}_{3}$ polymorphs," Journal of the Electrochemical Society, vol. 166, no. 3, pp. A5343-A5348, 2019.

[36] M. H. N. Assadi, M. Okubo, A. Yamada, and Y. Tateyama, "Oxygen redox in hexagonal layered $\mathrm{Na}_{\mathrm{x}} \mathrm{TMO}_{3}(\mathrm{TM}=4 \mathrm{~d}$ elements) for high capacity $\mathrm{Na}$ ion batteries," Journal of Materials Chemistry A, vol. 6, no. 8, pp. 3747-3753, 2018.

[37] J. Do, I. Kim, H. Kim, and Y. Jung, “Towards stable Na-rich layered transition metal oxides for high energy density sodium-ion batteries," Energy Storage Materials, vol. 25, pp. 62-69, 2020.

[38] S. Liu, F. Lu, H. Li et al., " $\mathrm{Na}_{2} \mathrm{Ru}_{0.8} \mathrm{Mn}_{0.2} \mathrm{O}_{3}$ : a novel cathode material for ultrafast sodium ion battery with large capacity and superlong cycle life," Journal of Power Sources, vol. 421, pp. 14-22, 2019.

[39] S. Song, M. Kotobuki, F. Zheng et al., "Na-rich layered $\mathrm{Na}_{2} \mathrm{R}-$ $\mathrm{u}_{0.95} \mathrm{Zr}_{0.05} \mathrm{O}_{3}$ cathode material for Na-ion batteries," Journal of Power Sources, vol. 342, pp. 685-689, 2017.
[40] Y. Qiao, S. Guo, K. Zhu et al., "Reversible anionic redox activity in $\mathrm{Na}_{3} \mathrm{RuO}_{4}$ cathodes: a prototype Na-rich layered oxide," Energy and Environmental Science, vol. 11, no. 2, pp. 299305, 2018.

[41] M. Otoyama, Q. Jacquet, A. Iadecola, M. Saubanère, G. Rousse, and J. M. Tarascon, "Synthesis and electrochemical activity of some $\mathrm{Na}(\mathrm{Li})$-rich ruthenium oxides with the feasibility to stabilize $\mathrm{Ru}^{6+}$," Advanced Energy Materials, vol. 9, no. 15, pp. 1-12, 2019.

[42] Y. Hu, T. Liu, C. Cheng et al., "Quantification of anionic redox chemistry in a prototype Na-rich layered oxide," ACS Applied Materials and Interfaces, vol. 12, no. 3, pp. 36173623, 2020.

[43] A. J. Perez, D. Batuk, M. Saubanère et al., "Strong oxygen participation in the redox governing the structural and electrochemical properties of Na-rich layered oxide $\mathrm{Na}_{2} \mathrm{IrO}_{3}$," Chemistry of Materials, vol. 28, no. 22, pp. 8278-8288, 2016.

[44] X. Zhang, Y. Qiao, S. Guo et al., "Manganese-based Na-rich materials boost anionic redox in high-performance layered cathodes for sodium-ion batteries," Advanced Materials, vol. 31, no. 27, pp. 1-9, 2019.

[45] P. E. Pearce, G. Rousse, O. M. Karakulina et al., " $\beta-\mathrm{Na}_{1.7} \mathrm{IrO}_{3}$ : a tridimensional $\mathrm{Na}$-ion insertion material with a redox active oxygen network," Chemistry of Materials, vol. 30, no. 10, pp. 3285-3293, 2018.

[46] N. Yabuuchi, R. Hara, K. Kubota, J. Paulsen, S. Kumakura, and S. Komaba, "A new electrode materials for rechargeable sodium batteries: P2-type $\mathrm{Na}_{2 / 3}\left[\mathrm{Mg}_{0.28} \mathrm{Mn}_{0.72}\right] \mathrm{O}_{2}$," Journal of Materials Chemistry A, vol. 2, no. 40, pp. 16851-16855, 2014.

[47] R. J. Clement, J. Billaud, A. R. Armstrong et al., "Structurally stable Mg-doped $\mathrm{P} 2-\mathrm{Na}_{2 / 3} \mathrm{Mn}_{1-\mathrm{y}} \mathrm{Mg}_{\mathrm{y}} \mathrm{O}_{2}$ sodium-ion battery cathodes with high rate performance: insights from electrochemical, NMR and diffraction studies," Energy \& Environmental Science, vol. 9, no. 10, pp. 3240-3251, 2016.

[48] U. Maitra, R. A. House, J. W. Somerville et al., "Oxygen redox chemistry without excess alkali-metal ions in $\mathrm{Na}_{2 / 3}\left[\mathrm{Mg}_{0.28} \mathrm{Mn}_{0.72}\right] \mathrm{O}_{2}$," Nature Chemistry, vol. 10, no. 3, pp. 288-295, 2018.

[49] N. Tapia-Ruiz, W. M. Dose, N. Sharma et al., "High voltage structural evolution and enhanced $\mathrm{Na}$-ion diffusion in P2$\mathrm{Na}_{2 / 3} \mathrm{Ni}_{1 / 3-\mathrm{x}} \mathrm{Mg}_{\mathrm{x}} \mathrm{Mg}_{2 / 3} \mathrm{O}_{2}(0 \leq \mathrm{x} \leq 0.2)$ cathodes from diffraction, electrochemical and ab initio studies," Energy \& Environmental Science, vol. 11, no. 6, pp. 1470-1479, 2018.

[50] Q.-C. Wang, J.-K. Meng, X.-Y. Yue et al., "Tuning P2structured cathode material by $\mathrm{Na}$-site $\mathrm{Mg}$ substitution for Na-ion batteries," Journal of the American Chemical Society, vol. 141, no. 2, pp. 840-848, 2019.

[51] H. J. Kim, A. Konarov, J. H. Jo et al., "Controlled oxygen redox for excellent power capability in layered sodiumbased compounds," Advanced Energy Materials, vol. 9, no. 32, article 1901181, 2019.

[52] R. A. House, U. Maitra, L. Jin et al., "What triggers oxygen loss in oxygen redox cathode materials?," Chemistry of Materials, vol. 31, no. 9, pp. 3293-3300, 2019.

[53] J. Vergnet, M. Saubanere, M.-L. Doublet, and J.-M. Tarascon, "The structural stability of P2-layered Na-based electrodes during anionic redox," Joule, vol. 4, no. 2, pp. 1-15, 2020.

[54] L. Yang, Z. Lium, S. Liu et al., "Superiority of native vacancies in activating anionic redox in P2-type $\mathrm{Na}_{2 / 3}\left[\mathrm{Mn}_{7 / 9} \mathrm{Mg}_{1 / 9} \square_{1 / 9}\right] \mathrm{O}_{2}$," Nano Energy, vol. 78, article 105172, 2020. 
[55] X. Bai, A. Iadecola, J.-M. Tarascon, and P. Rozier, "Decoupling the effect of vacancies and electropositive cations on the anionic redox processes in $\mathrm{Na}$ based $\mathrm{P} 2$-type layered oxides," Energy Storage Materials, vol. 31, pp. 146-155, 2020.

[56] C. Cheng, M. Ding, T. Yan et al., "Exploring the charge compensation mechanism of $\mathrm{P} 2$-type $\mathrm{Na}_{0.6} \mathrm{Mg}_{0.3} \mathrm{Mn}_{0.7} \mathrm{O}_{2}$ cathode materials for advanced sodium-ion batteries," Energies, vol. 13, no. 21, p. 5729, 2020.

[57] A. Konarov, J. H. Jo, J. U. Choi et al., "Exceptionally highly stable cycling performance and facile oxygen-redox of manganese-based cathode materials for rechargeable sodium batteries," Nano Energy, vol. 59, pp. 197-206, 2019.

[58] X. Bai, M. Sathiya, B. Mondoza-sanchex et al., "Anionic redox activity in a newly $\mathrm{Zn}$-doped sodium layred oxide P2$\mathrm{Na}_{2 / 3} \mathrm{Mn}_{1-\mathrm{y}} \mathrm{Zn}_{\mathrm{y}} \mathrm{O}_{2}(0<\mathrm{y}<0.23)$," Advanced Energy Materials, vol. 8, no. 32, article 1802379, 2018.

[59] W. Zheng, Q. Liu, Z. Wang et al., "Stabilizing the oxygen lattice and reversible oxygen redox in Na-deficient cathode oxides," Journal of Power Sources, vol. 43, p. 227086, 2019.

[60] A. Konarov, H. J. Kim, J.-H. Jo et al., "High-voltage oxygenredox-based cathode for rechargeable sodium-ion batteries," Advanced Energy Materials, vol. 10, no. 24, article 2001111, 2020.

[61] C. Ma, J. Alvarado, J. Xu et al., "Exploring oxygen activity in the high energy P2-type $\mathrm{Na}_{0.78} \mathrm{Ni}_{0.23} \mathrm{Mn}_{0.69} \mathrm{O}_{2}$ cathode material for Na-ion batteries," Journal of the American Chemical Society, vol. 139, no. 13, pp. 4835-4845, 2017.

[62] C. Cheng, S. Li, T. Liu et al., "Elucidation of anionic and cationic redox reactions in a prototype sodium-layered oxide cathode," ACS Applied Materials \& Interfaces, vol. 11, no. 44, pp. 41304-41312, 2019.

[63] W. Kong, W. Yang, D. Ning et al., "Tuning anionic/cationic redox chemistry in a P2-type $\mathrm{Na}_{0.67} \mathrm{Mn}_{0.5} \mathrm{Fe}_{0.5} \mathrm{O}_{2}$ cathode material via a synergic strategy," Science China Materials, vol. 63, no. 9, pp. 1703-1718, 2020.

[64] W. Kong, R. Gao, Q. Li et al., "Simultaneously tuning cationic and anionic redox in a $\mathrm{P} 2-\mathrm{Na}_{0.67} \mathrm{Mn}_{0.75} \mathrm{Ni}_{0.25} \mathrm{O}_{2}$ cathode material through synergic $\mathrm{Cu} / \mathrm{Mg}$ co-doping," Journal of Materials Chemistry, vol. 7, no. 15, pp. 9099-9109, 2019.

[65] Y. Zhang, M. Wu, J. Ma et al., "Revisiting the $\mathrm{Na}_{2 / 3} \mathrm{Ni}_{1 / 3} \mathrm{Mn}_{2 / 3} \mathrm{O}_{2}$ cathode: oxygen redox chemistry and oxygen release suppression," ACS Central Science, vol. 6, no. 2, pp. 232-240, 2020.

[66] W. Zuo, F. Ren, Q. Li et al., "Insights of the anionic redox in P2- $\mathrm{Na}_{0.67} \mathrm{Ni}_{0.33} \mathrm{Mn}_{0.67} \mathrm{O}_{2}$," Nano Energy, vol. 78, p. 105285, 2020.

[67] K. Dai, J. Mao, Z. Zhuo et al., "Negligible voltage hysteresis with strong anionic redox in conventional battery electrode," Nano Energy, vol. 74, p. 104831, 2020.

[68] C. Hakim, N. Sabi, L. A. Ma et al., "Understanding the redox process upon electrochemical cycling of the P2$\mathrm{Na}_{0.78} \mathrm{Co}_{1 / 2} \mathrm{Mn}_{1 / 3} \mathrm{Ni}_{1 / 6} \mathrm{O}_{2}$ electrode material for sodium-ion batteries," Communications Chemistry, vol. 3, no. 1, p. 9, 2020.

[69] P.-F. Wang, Y. Xiao, N. Piao et al., "Both cationic and anionic redox chemistry in a P2-type sodium layered oxide," Nano Energy, vol. 69, p. 104474, 2020.

[70] W. Zheng, Q. Liu, Z. Wang et al., "Oxygen redox activity with small voltage hysteresis in $\mathrm{Na}_{0.67} \mathrm{Cu}_{0.28} \mathrm{Mn}_{0.72} \mathrm{O}_{2}$ for sodiumion batteries," Energy Storage Materials, vol. 28, pp. 300-306, 2020.
[71] I. Abate, S. Y. Kim, C. Das Pemmaraju et al., "The role of metal substitution in tuning anion redox in sodium metal layered oxides revealed by X-ray spectroscopy and theory," Angewandte Chemie International Edition, vol. 60, no. 19, pp. 10880-10887, 2020.

[72] L. Li, H. Wang, W. Han et al., "Understanding oxygen redox in $\mathrm{Cu}$-doped $\mathrm{P} 2-\mathrm{Na}_{0.67} \mathrm{Mn}_{0.8} \mathrm{Fe}_{0.1} \mathrm{Co}_{0.1} \mathrm{O}_{2}$ cathode materials for Na-ion batteries," Journal of the Electrochemical Society, vol. 165, no. 16, pp. A3854-A3861, 2018.

[73] E. Adamczyk and V. Pralong, " $\mathrm{Na}_{2} \mathrm{Mn}_{3} \mathrm{O}_{7}$ : a suitable electrode material for Na-ion batteries?," Chemistry of Materials, vol. 29, no. 11, pp. 4645-4648, 2017.

[74] B. Mortemard de Boisse, S. I. Nishimura, E. Watanabe et al., "Highly reversible oxygen-redox chemistry at $4.1 \mathrm{~V}$ in $\mathrm{Na}_{4 / 7}$ ${ }_{-x}\left[\square_{1 / 7} \mathrm{Mn}_{6 / 7}\right] \mathrm{O}_{2}$ ( $\square$ : Mn vacancy)," Advanced Energy Materials, vol. 8, no. 20, pp. 2-8, 2018.

[75] C. Zhao, Q. Wang, Y. Lu et al., "Decreasing transition metal triggered oxygen redox activity in Na-deficient oxides," Energy Storage Materials, vol. 20, pp. 395-400, 2019.

[76] Y. Li, X. Wang, Y. Gao et al., "Native vacancy enhanced oxygen redox reversibility and structural robustness," Advanced Energy Materials, vol. 9, no. 4, pp. 1-9, 2019.

[77] Q. Wang, W. Yang, F. Kang, and B. Li, " $\mathrm{Na}_{2} \mathrm{Mn}^{3+}{ }_{0.3} \mathrm{Mn}^{4+}{ }_{2.7-}$ $\mathrm{O}_{6.85}$ : a cathode with simultaneous cationic and anionic redox in Na-ion battery," Energy Storage Materials, vol. 14, pp. 361-366, 2018.

[78] A. Tsuchimoto, X. M. Shi, K. Kawai et al., "Nonpolarizing oxygen-redox capacity without $\mathrm{O}-\mathrm{O}$ dimerization in $\mathrm{Na}_{2} \mathrm{Mn}_{3} \mathrm{O}_{7}$," Nature Communications, vol. 12, no. 1, pp. 17, 2021.

[79] I. I. Abate, C. Das Pemmaraju, S. Y. Kim et al., "Coulombically-stabilized oxygen hole polarons enable fully reversible oxygen redox," Energy \& Environmental Science, 2021.

[80] B. Song, M. Tang, E. Hu et al., "Understanding the lowvoltage hysteresis of anionic redox in $\mathrm{Na}_{2} \mathrm{Mn}_{3} \mathrm{O}_{7}$," Chemistry of Materials, vol. 31, no. 10, pp. 3756-3765, 2019.

[81] D. A. Kitchaev, J. Vinckeviciute, and A. Van Der Ven, "Delocalized metal-oxygen $\pi$-redox is the origin of anomalous nonhysteretic capacity in $\mathrm{Li}$-ion and $\mathrm{Na}$-ion cathode materials," Journal of the American Chemical Society, vol. 143, no. 4, pp. 1908-1916, 2021.

[82] K. Dai, J. Wu, Z. Zhuo et al., "High reversibility of lattice oxygen redox quantified by direct bulk probes of both anionic and cationic redox reactions," Joule, vol. 3, no. 2, pp. 518$541,2019$.

[83] J. Wu, Z.-x. Shen, and W. Yang, "Redox mechanism in Naion battery cathodes probed by advanced soft X-ray spectroscopy," Frontiers in Chemistry, vol. 8, article 816, 2020.

[84] D. Kim, M. Cho, and K. Cho, "Rational design of $\mathrm{Na}\left(\mathrm{Li}_{1 / 3} \mathrm{Mn}_{2 / 3}\right) \mathrm{O}_{2}$ operated by anionic redox reactions for advanced sodium-ion batteries," Advanced Materials, vol. 29, no. 33, pp. 1-8, 2017.

[85] Q. Wang, S. Mariyappan, G. Rousse et al., "Unlocking anionic redox activity in O3-type sodium 3d layered oxides via $\mathrm{Li}$ substitution," Nature Materials, vol. 20, no. 3, pp. 353-361, 2021.

[86] N. Voronina, N. Yaqoob, H. J. Kim et al., “A new approach to stable cationic and anionic redox activity in O3-layered cathode for sodium-ion batteries," Advanced Energy Materials, vol. 2, p. 2100901, 2021. 
[87] A. J. Perez, G. Rousse, and J. M. Tarascon, "Structural instability driven by $\mathrm{Li} / \mathrm{Na}$ competition in $\mathrm{Na}\left(\mathrm{Li}_{1 / 3} \mathrm{Ir}_{2 / 3}\right) \mathrm{O}_{2}$ cathode material for $\mathrm{Li}$-ion and $\mathrm{Na}$-ion batteries," Inorganic Chemistry, vol. 58, no. 22, pp. 15644-15651, 2019.

[88] X. Rong, J. Liu, E. Hu et al., "Structure-induced reversible anionic redox activity in Na layered oxide cathode," Joule, vol. 2, no. 1, pp. 125-140, 2018.

[89] H. Xu, S. Guo, and H. Zhou, "Review on anionic redox in sodium-ion batteries," Journal of Materials Chemistry A, vol. 7, no. 41, pp. 23662-23678, 2019.

[90] J. Wu, Z. Zhuo, X. Rong et al., "Dissociate lattice oxygen redox reactions from capacity and voltage drops of battery electrode," Science Advances, vol. 6, no. 6, article eaaw3871, 2020.

[91] E. J. Kim, L. A. Ma, D. M. Pickup et al., "Vacancy-enhanced oxygen redox reversibility in P3-type magnesium-doped sodium manganese oxide $\mathrm{Na}_{0.67} \mathrm{Mg}_{0.2} \mathrm{Mn}_{0.8} \mathrm{O}_{2}$," ACS Applied Energy Materials, vol. 3, no. 11, pp. 10423-10434, 2020.

[92] J. Min, H. Li, Y. Qiao et al., "Elucidating anionic redox chemistry in P3 layered cathode for Na-ion batteries," ACS Applied Materials \& Interfaces, vol. 12, no. 34, pp. 38249-38255, 2020.

[93] N. Li, S. Sallis, J. K. Papp, M. C. BD, W. Yang, and W. Tong, "Correlating the phase evolution and anionic redox in Cofree Ni-Rich layered oxide cathodes," Nano Energy, vol. 78, article 105365, 2020.

[94] E. J. Kim, L. A. Ma, L. C. Duan et al., "Oxygen redox activity through a reductive coupling mechanism in the P3-type nickel-doped sodium manganese oxide," ACS Applied Materials \& Interfaces, vol. 3, no. 1, pp. 184-191, 2020.

[95] E. J. Kim, K. Mofredj, D. M. Pickup, A. V. Chadwick, J. T. S. Irvine, and A. R. Armstrong, "Activation of anion redox in P3 structure cobalt-doped sodium manganese oxide via introduction of transition metal vacancies," Journal of Power Sources, vol. 481, p. 229010, 2021.

[96] M. Jia, Y. Qiao, X. Li, K. Jiang, and H. Zhou, "Unraveling the anionic oxygen loss and related structural evolution within O3-type $\mathrm{Na}$ layered oxide cathodes," Journal of Materials Chemistry A, vol. 7, no. 35, pp. 20405-20413, 2019.

[97] Z. Shadike, Y. N. Zhou, L. L. Chen et al., "Antisite occupation induced single anionic redox chemistry and structural stabilization of layered sodium chromium sulfide," Nature Communications, vol. 8, no. 1, pp. 1-9, 2017.

[98] T. Wang, G. X. Ren, Z. Shadike et al., “Anionic redox reaction in layered $\mathrm{NaCr}_{2 / 3} \mathrm{Ti}_{1 / 3} \mathrm{~S}_{2}$ through electron holes formation and dimerization of S-S," Nature Communications, vol. 10, no. 1, p. 4458, 2019.

[99] M. S. Whittingham, "Electrical energy storage and intercalation chemistry," Science, vol. 192, no. 4244, pp. 1126-1127, 1976.

[100] J. Rouxel, "Anion-cation redox competition and the formation of new compounds in highly covalent systems," Angewandte Chemie - International Edition in English, vol. 35, no. 17, pp. 1053-1059, 1996.

[101] Y. Lyu, L. Ben, Y. Sun et al., "Atomic insight into electrochemical inactivity of lithium chromate $\left(\mathrm{LiCrO}_{2}\right)$ : irreversible migration of chromium into lithium layers in surface regions," Journal of Power Sources, vol. 273, pp. 1218-1225, 2015.
[102] S. Kikkawa, S. Miyazaki, and M. Koizumi, "Sodium deintercalation from $\alpha-\mathrm{NaFeO}_{2}$," Materials research bulletin, vol. 20, no. 4, pp. 373-377, 1985.

[103] N. Yabuuchi, H. Yoshida, and S. Komaba, "Crystal structures and electrode performance of alpha- $\mathrm{NaFeO}_{2}$ for rechargeable sodium batteries," Electrochemistry, vol. 80, no. 10, pp. 716$719,2012$.

[104] J. Zhao, L. Zhao, N. Dimov, S. Okada, and T. Nishida, “Electrochemical and thermal properties of $\alpha-\mathrm{NaFeO}_{2}$ cathode for Na-ion batteries," Journal of The Electrochemical Society, vol. 160, no. 5, pp. A3077-A3081, 2013.

[105] E. Lee, D. E. Brown, E. E. Alp et al., "New insights into the performance degradation of $\mathrm{Fe}$-based layered oxides in sodium-ion batteries: instability of $\mathrm{Fe}^{3+} / \mathrm{Fe}^{4+}$ redox in $\alpha$ $\mathrm{NaFeO}_{2}$," Chemistry of Materials, vol. 27, no. 19, pp. 67556764, 2015.

[106] Y. Li, Y. Gao, X. Wang et al., "Iron migration and oxygen oxidation during sodium extraction from $\mathrm{NaFeO}_{2}$," Nano Energy, vol. 47, pp. 519-526, 2018.

[107] D. Susanto, M. K. Cho, G. Ali et al., "Anionic redox activity as a key factor in the performance degradation of $\mathrm{NaFeO}_{2}$ cathodes for sodium ion batteries," Chemistry of Materials, vol. 31, no. 10, pp. 3644-3651, 2019.

[108] J. Zhang, B. Su, A. Kitajou et al., “Activating abnormal capacity in stoichiometric $\mathrm{NaVO}_{3}$ as cathode material for sodiumion battery," Journal of Power Sources, vol. 400, pp. 377-382, 2018.

[109] B. Su, S. Wu, H. Liang et al., "High-performance $\mathrm{NaVO}_{3}$ with mixed cationic and anionic redox reactions for $\mathrm{Na}$-ion battery applications," Chemistry of Materials, vol. 32, no. 20, pp. 8836-8844, 2020.

[110] X. Gao, D. Wang, R. Lian et al., "Electronic properties, phase transformation, and anionic redox of monoclinic $\mathrm{Na}_{2} \mathrm{MnO}_{3}$ cathode material for sodium-ion batteries: first-principle calculations," ChemElectroChem, vol. 6, no. 15, pp. 3987-3993, 2019.

[111] L. Yang, J. M. L. del Amo, Z. Shadike et al., "A Co- and Nifree $\mathrm{P} 2 / \mathrm{O} 3$ biphasic lithium stabilized layered oxide for sodium-ion batteries and its cycling behavior," Advanced Functional Materials, vol. 30, no. 42, pp. 1-11, 2020.

[112] B. Hu, F. Geng, C. Zhao et al., "Deciphering the origin of high electrochemical performance in a novel Ti-substituted $\mathrm{P} 2 / \mathrm{O} 3$ biphasic cathode for sodium-ion batteries," ACS Applied Materials and Interfaces, vol. 12, no. 37, pp. 41485-41494, 2020.

[113] R. J. Clément, Z. Lun, and G. Ceder, "Cation-disordered rocksalt transition metal oxides and oxyfluorides for high energy lithium-ion cathodes," Energy \& Environmental Science, vol. 13, no. 2, pp. 345-373, 2020.

[114] K. Sato, M. Nakayama, A. M. Glushenkov et al., "Na-excess cation-disordered rocksalt oxide: $\mathrm{Na}_{1.3} \mathrm{Nb}_{0.3} \mathrm{Mn}_{0.4} \mathrm{O}_{2}$," Chemistry of Materials, vol. 29, no. 12, pp. 5043-5047, 2017.

[115] T. Kobayashi, W. Zhao, H. B. Rajendra, K. Yamanaka, T. Ohta, and N. Yabuuchi, "Nanosize cation-disordered rocksalt oxides: $\mathrm{Na}_{2} \mathrm{TiO}_{3}-\mathrm{NaMnO}_{2}$ binary system," Small, vol. 16, no. 12 , pp. $1-6,2020$. 